\title{
Comparative experimental study of hot-rolled and cold- formed rectangular hollow sections
}

\author{
L Gardner, N Saari and F Wang \\ Imperial College London
}

\begin{abstract}
Square and rectangular hollow sections are generally produced either by hot-rolling or coldforming. Cross-sections of nominally similar geometries, but from the two different production routes may vary significantly in terms of their general material properties, geometric imperfections, residual stresses, corner geometry and material response and general structural behaviour and load-carrying capacity. In this paper, an experimental programme comprising tensile coupon tests on flat and corner material, measurements of geometric imperfections and residual stresses, stub column tests and simple and continuous beam tests is described. The results of the tests have been combined with other available test data on square and rectangular hollow sections and analysed. Enhancements in yield and ultimate strengths, beyond those quoted in the respective mill certificates, were observed in the corner regions of the cold-formed sections - these are caused by cold-working of the material during production, and predictive models have been proposed. Initial geometric imperfections were generally low in both the hot-rolled and cold-formed sections, with larger imperfections emerging towards the ends of the cold-formed members - these were attributed largely to the release of through thickness residual stresses, which were themselves quantified. The results of the stub column and simple bending tests were used to assess the current slenderness limits given in Eurocode 3, including the possible dependency on
\end{abstract}


production route, whilst the results of the continuous beam tests were evaluated with reference to the assumptions typically made in plastic analysis and design. Current slenderness limits, assessed on the basis of bending tests, appear appropriate, though the Class 3 slenderness limit, assessed on the basis of compression tests, seems optimistic. Of the features investigated, strain hardening characteristics of the material were identified as being primarily responsible for the differences in structural behaviour between hot-rolled and coldformed sections.

Keywords: Bending, Cold-formed sections, Continuous beams, Corner geometry, Geometric imperfections, Hollow sections, Hot-rolled sections, Material properties, Residual stresses, RHS, SHS, Strain hardening, Stub column tests, Tensile coupon tests, Tubular sections

\section{Introduction}

Structural hollow sections are widely used in a range of engineering applications, offering structural efficiency, aesthetic solutions and the possibility of being concrete-filled to achieve greater load-carrying capacity. There are a variety of means of producing square and rectangular hollow sections (SHS and RHS, respectively), the principal two being hot-rolling and cold-forming, with two further, less common alternative techniques involving welding two channel sections tip-to-tip or welding four flat plates at their corners. Cold-formed sections may be subsequently stress relieved. It therefore follows that SHS and RHS of nominally similar geometries may exhibit different structural characteristics owing to the different strain histories and thermal actions that may be experienced during production. 
Hot-rolling of structural steel sections is generally carried out above the re-crystallisation temperature of the material (typically around $850^{\circ} \mathrm{C}$ ) in accordance with EN 10210-1 [1]; the resulting sections have homogeneous material properties, consistent hardness, good ductility and relatively low residual stresses. Tight corner radii, which often facilitate welding between members, can also be achieved [2]. Conversely, cold-formed sections are produced at ambient temperatures in accordance with EN 10219-2 [3], and undergo plastic deformation during forming. Plastic deformation causes cold-working of the material, resulting in enhanced strength, but a corresponding loss of ductility. Non-homogeneity of material properties and variation in hardness around the section typically arise due to the uneven levels of plastic deformation experienced during forming; the corner regions of cold-formed sections, in particular, undergo high levels of cold-work, and larger corner radii are specified in EN 10219-2 to avert corner cracking. Also associated with non-uniform plastic deformation is the formation of residual stresses - in cold-formed structural sections, these generally appear as through-thickness bending residual stresses, as discussed later in this paper. Further information on the properties and behaviour of cold-formed sections can be found in [4].

Overall, disparities between hot-rolled and cold-formed hollow sections may be observed in material properties, geometric imperfections, residual stresses, corner geometry and material response as well as the general structural behaviour and load-carrying capacity of the produced sections. A comparative study of these characteristics is presented herein.

Direct comparisons between hot-rolled and cold-formed structural steel sections are relatively scarce, but many of the above properties have been studied in hot-rolled steel sections [5-7], cold-formed steel sections [8-11] and cold-formed stainless steel sections [12-15]. The 
influence of different production routes on the behaviour of structural carbon steel [16] and structural stainless steel [17-19] members, which tend to display a more pronounced response to cold-work, has also been investigated. In this paper, a series of investigations are described to highlight the distinctions between hot-rolled and cold-formed steel box sections.

\section{Experimental Investigation}

\subsection{Test Specimens}

An experimental programme comprising tensile coupon tests on flat and corner material, measurements of geometric imperfections and residual stresses, stub column tests and simple and continuous beam tests was carried out to investigate the structural behaviour of hot-rolled and cold-formed square and rectangular hollow sections (SHS and RHS, respectively). All tests and measurements were performed in the Structures Laboratory of the Department of Civil and Environmental Engineering at Imperial College London.

A total of ten structural hollow sections were examined - five hot-rolled and five cold-formed of the following nominal section sizes $-100 \times 100 \times 4,60 \times 60 \times 4,60 \times 40 \times 4,40 \times 40 \times 4$ and $40 \times 40 \times 3$. The nominal yield strength of the hot-rolled tubes was $355 \mathrm{~N} / \mathrm{mm}^{2}$ while that of the cold-formed tubes was $235 \mathrm{~N} / \mathrm{mm}^{2}$. Ten flat and six corner tensile coupons together with twenty stub columns were tested. Geometric imperfections were measured along the centrelines of the four faces of all twenty stub columns, whilst residual stresses were quantified from the flat and corner coupons, which were subsequently subjected to tensile testing. 


\subsection{Tensile Coupon Tests}

The basic stress-strain properties of the investigated hot-rolled and cold-formed sections were obtained through tensile coupon tests. These tests were conducted in accordance with EN 10002-1 [20]. For each of the ten SHS and RHS specimens, one flat parallel coupon was machined from the face opposite the weld. Corner coupons were also extracted and tested for each of the five cold-formed sections in order to examine the influence of the high localised cold-work, and for one of the hot-rolled sections to confirm uniformity of properties. Fig. 1 shows the location of the flat and corner tensile coupons extracted from the hot-rolled and cold-formed box sections for this study, together with the adopted dimension labelling system.

The nominal dimensions of flat coupons were $350 \times 15 \mathrm{~mm}$ for the smaller cross-section sizes $(40 \times 40 \times 4 \mathrm{~mm}$ and $40 \times 40 \times 3 \mathrm{~mm})$ and $320 \times 20 \mathrm{~mm}$ for the larger cross-sections. All tensile tests were performed using an Amsler $350 \mathrm{kN}$ hydraulic testing machine. Linear electrical strain gauges were affixed at the midpoint of each side of the tensile coupons and a series of overlapping proportional gauge lengths was marked onto the surface of the coupons to determine the elongation at fracture. Load, strain, displacement and input voltage were all recorded using the data acquisition equipment DATASCAN and logged using the DALITE and DSLOG computer packages.

Typical measured stress-strain curves from hot-rolled and cold-formed material (SHS $60 \times 60 \times 3-\mathrm{HR}$ and SHS $60 \times 60 \times 3-\mathrm{CF})$ are shown in Fig. 2, with the hot-rolled material displaying the anticipated sharply defined yield point, yield plateau and subsequent strain hardening whilst the cold-formed material exhibited a more rounded response. The key 
results from all tensile coupon tests, together with the corresponding mill certificate (virgin) material properties, are given in Table 1. The specimens were labelled according to their different section geometries and production routes $(\mathrm{HR}=$ hot-rolled and $\mathrm{CF}=$ cold-formed $)$, while a ' $\mathrm{C}$ ' was appended to the specimen designation to indicate corner coupon. In Table 1, $\sigma_{y}$ and $\sigma_{u}$ refer to the yield and ultimate strengths of the material, respectively, E denotes Young's modulus and $\varepsilon \mathrm{f}$ is the plastic strain at fracture. For the hot-rolled sections a distinct yield stress was observed (with the lower yield stress being reported in Table 1), but for the cold-formed sections the yield stress was taken as the $0.2 \%$ proof stress (as marked in Fig. 2).

\subsection{Geometric Imperfection Measurements}

Measurements of local geometric imperfections were performed on all four faces of twenty stub columns - two specimens for each of the ten box sections. The experimental set-up for the imperfection measurements employed in the present study was similar to that adopted by Schafer and Peköz [8] and Gardner and Nethercot [13] - each specimen was mounted on the bed of a milling machine where the flat surface provided a reference plane for the measurements. A displacement transducer, fitted in the head of the milling machine, was positioned at the centreline of each face of the specimen and driven along the length. Deviation from the flat condition was monitored and recorded at $10 \mathrm{~mm}$ intervals.

The measurements revealed high geometric imperfections associated with flaring at the ends of the stub columns; this was most apparent in the cold-formed sections, and is caused by the through-thickness residual stresses, generated during the forming process, and released upon cutting of the sections. Imperfections due to end flaring were isolated and deducted from the measured results; the resulting imperfection amplitudes are examined and discussed in Section 3.2. 


\subsection{Residual Stress Measurements}

Following the sectioning process, the released tensile coupons were observed to curve from their initial flat geometry, indicating the presence of through-thickness bending residual stresses. This curvature was most evident in the cold-formed sections. In order to measure the bending residual stresses, strain gauges were attached to the inner and outer surfaces of the coupons. After initial strain readings were taken in the curved state, the coupons were deformed to their original flat condition, whereupon final strain readings were taken.

Following the residual strain measurements, tensile coupon tests were performed on each of the coupons to provide material data (Table 1), against which the residual stress magnitudes could be compared. Derivation of residual stresses from the measured strains is described in Section 3.3. Clearly this process does not capture overall extension or shortening of the released coupons, and hence membrane residual stresses were not quantified in this study.

\subsection{Stub Column Tests}

A total of twenty stub columns were tested under pure axial compression - two repeated tests, denoted ' 1 ' and ' 2 ' in Table 2, for each of the ten box sections. The nominal length of the stub columns was selected as four times the larger cross-section dimension in order to avoid overall buckling but still include a representative distribution of geometric imperfections and residual stresses. The stub column specimens were cut using a rotary hacksaw, and the ends of each specimen were machined flat and square to ensure a uniform distribution of loading during testing. Four linear electrical resistance strain gauges were affixed to each specimen at mid-height, and in the orientation shown in Fig. 3. The strain gauges were positioned at a distance of four times the material thickness from the corners of the specimens for the larger 
sections $(100 \times 100 \times 4 \mathrm{~mm}$ and $60 \times 60 \times 3 \mathrm{~mm})$, and a distance of three times the material thickness from the corners for the remaining specimens. Measurements of geometry, including local geometric imperfections (see Section 2.3), were taken prior to the testing.

The compression tests were carried out in a $300 \mathrm{~T}$ Amsler hydraulic testing machine; the experimental set-up is shown in Fig. 4. The specimens were loaded between the two parallel end platens of the testing machine and four displacement transducers (LVDTs) were employed to measure average end-shortening. A similar testing arrangement has been successfully employed in previous studies [7, 13]. Uniformity of corner strains (variation between strains at any corner from the average strain being less than 5\%) at low load levels confirmed that the specimens were loaded concentrically. Readings of load, strain, end shortening and input voltage were recorded at 2 second intervals using Datascan acquisition equipment and logged using the Dalite software.

The geometric properties of the stub columns and the key test results are summarised in Table 2, where $\mathrm{L}$ is specimen length, $\mathrm{D}$ and $\mathrm{B}$ are depth and breadth of the sections, respectively, $\mathrm{t}$ is material thickness, $\mathrm{r}_{\mathrm{i}}$ is average internal corner radius, $\mathrm{A}$ is the gross crosssectional area and $\mathrm{F}_{\mathrm{u}}$ is the ultimate load achieved by the stub columns. The cross-sectional areas of the sections were calculated taking due account of the corner geometry. The normalised load-end shortening curves $-\mathrm{F} / A \sigma_{\mathrm{y}}$ versus $\delta / \mathrm{L}$, where $\mathrm{F}$ is the applied load, $\mathrm{A}$ is the measured cross-sectional area, $\sigma_{\mathrm{y}}$ is the measured tensile yield strength, $\delta$ is the recorded end-shortening and $\mathrm{L}$ is the measured specimen length - for all stub columns investigated in this study are plotted in Fig. 5. A distinct yield point may be observed for the hot-rolled specimens, while the response of the cold-formed specimens is more rounded. As anticipated, greater load carrying capacity (relative to the yield load) and superior deformation capacity 
can be seen in stocky sections. All stub columns failed by local buckling, either prior to or subsequent to the onset of yielding - typical failure modes (for stub columns SHS $100 \times 100 \times 4-C F 1$ and CF2) are shown in Fig. 6. Analysis of the results of the stub column tests is presented in Section 3.4.

\subsection{Beam tests}

A series of simple beam tests and continuous beam tests (with two loading configurations) were performed on the hot-rolled and cold-formed steel hollow sections to assess moment capacity, rotation capacity and collapse loads.

\subsubsection{Simple beam tests}

A total of six simple beam tests were carried out. The nominal section sizes were RHS $60 \times 40 \times 4$, SHS $40 \times 40 \times 4$ and SHS $40 \times 40 \times 3$; one hot-rolled and one cold-formed specimen of each size were examined. The geometric properties of each specimen have been recorded in Table 3; the symbols employed are as defined in previous sections of this paper. The calculated elastic and plastic moduli, $\mathrm{W}_{\mathrm{el}}$ and $\mathrm{W}_{\mathrm{pl}}$, respectively (determined taking suitable account of the corner geometry) are also presented in Table 3.

The symmetrical three-point simply-supported bending test arrangement is shown in Fig. 7. The span of the beams was fixed at $1100 \mathrm{~mm}$ and testing was displacement-controlled at a rate of $3.0 \mathrm{~mm} / \mathrm{min}$. Simple support conditions were achieved by means of steel rollers. The specimens extended approximately $50 \mathrm{~mm}$ beyond each end support. Wooden blocks were inserted into the tubular specimens at the loading point to prevent local bearing failure. Steel plates (50mm wide and $10 \mathrm{~mm}$ thick) were also employed at the points of support and load introduction. For each specimen, two strain gauges were adhered to the tensile and 
compressive flanges, at a distance of $60 \mathrm{~mm}$ from the loading point. End rotations and midspan deflections were recorded digitally throughout the tests by means of LVDTs.

The key results from the six three-point bending tests are summarised in Table 4. The following values are presented: the measured ultimate test bending moment $\mathrm{M}_{\mathrm{u}}$ (at mid-span), the calculated elastic and plastic moment capacities, $\mathrm{M}_{\mathrm{el}}$ and $\mathrm{M}_{\mathrm{pl}}$ respectively, the normalised ultimate moment $\left(\mathrm{Mu}_{\mathrm{u}} / \mathrm{Mel}_{\mathrm{el}}\right.$ and $\left.\mathrm{Mu} / \mathrm{Mpl}_{\mathrm{pl}}\right)$, the elastic rotation at the plastic moment $\theta_{\mathrm{pl}}$, the total rotation at ultimate moment $\theta_{\mathrm{u}}$, the total rotation upon reaching the plastic moment on the unloading path $\theta_{\text {rot, }}$ and where $\theta_{\text {rot }}$ was not attained, the maximum recorded test rotation $\theta_{\max }$. Note that $\mathrm{Mel}_{\mathrm{el}}$ and $\mathrm{M}_{\mathrm{pl}}$ have been calculated on the basis of the measured geometry and the measured tensile yield strength (or $0.2 \%$ proof strength) of the flat material for each section, and that $\theta_{\mathrm{pl}}$ has been determined on the basis of the measured flexural rigidity (EI) from the bending tests, which varied from the theoretical (EI) - tensile Young's modulus multiplied by second moment of area as calculated from measured geometry - by a maximum of 5\%.

The rotation capacity $\mathrm{R}$ of the test specimens was determined from Eq. (1) on the basis of the recorded moment-rotation curves.

$$
\mathrm{R}=\frac{\theta_{\mathrm{rot}}}{\theta_{\mathrm{pl}}}-1
$$

Symbols and determination of rotation capacity are illustrated in Fig. 8, where $M$ is the bending moment at mid-span and $\theta$ is the rotation of the plastic hinge (taken as the sum of the two end rotations).

The normalised moment-rotation curves for the six simple beam tests are presented in Figs 911. The graphs are arranged such that a direct comparison between the hot-rolled and cold- 
formed sections of similar nominal dimensions can be made. In one out of the six simple bending tests, the bending moment fell below $\mathrm{Mpl}_{\mathrm{pl}}$ on the unloading path prior to the termination of the experiment, whilst for the remaining specimens rotation capacity was calculated on the basis of $\theta_{\max }$ (the maximum attained rotation prior to the test being terminated), though this does not necessarily reflect the full rotation capacity of the specimens [21]. Despite the full rotation capacity not being attained in some tests, all specimens were deemed to have sufficient rotation capacity $(\mathrm{R}>3)$ for plastic design according to Eurocode 3 [22], as shown in Table 4. A typical deformed test specimen (SHS $40 \times 40 \times 3-\mathrm{CF}$ ), exhibiting inelastic local buckling of the compression flange and upper portion of the webs, is shown in Fig. 12.

\subsubsection{Continuous beam tests}

A total of 12 continuous beam tests was conducted. As in the simply-supported arrangement, three nominal section sizes - RHS $60 \times 40 \times 4$, SHS $40 \times 40 \times 4$ and SHS $40 \times 40 \times 3$ - were considered; for each section size, two hot-rolled and two cold-formed specimens were tested. The measured geometric properties of the test specimens have been presented in Table 5; symbols have been previously defined.

Two symmetrical 5-point bending test configurations were employed as shown in Figs 13 and 14. Similar to the three-point bending tests, symmetrical span lengths of $1100 \mathrm{~mm}$ and displacement-controlled testing at a rate of $3 \mathrm{~mm} / \mathrm{min}$ were chosen. In the first configuration, designated ' $1 / 2$ span' in Table 5, the loads were applied at the centre of the two spans, as shown in Fig. 13. In the second configuration, designated '1/3 span' in Table 5, the loads were applied at $366.7 \mathrm{~mm}$ from the central support, as shown in Fig. 14. The principal purpose of adopting these two test configurations was to vary the ratio of load levels between 
the formation of the first hinge and the final collapse mechanism. As for the simply supported beams, steel rollers were employed to achieve rotationally-free conditions at the beam ends and central support, and steel plates and wooden blocks were introduced at the loading points and central support to prevent local bearing failure. Four displacement transducers (LVDTs 1, 2, 3 and 4) were used to measure the end rotations of the beams while two additional transducers (LVDTs 5 and 6) measured rotation at the central support. Two further LVDTs (LVDTs 7 and 8) were employed to obtain the deflections at the loading points. The locations of the displacement transducers are shown in Figs 13 and 14.

The key results from the continuous beam tests are presented in Table 6; the theoretical load at which the first hinge forms $F_{h 1}$, the theoretical plastic collapse load $F_{\text {coll, }}$, the ultimate load attained in the tests $F_{u}$ and the ratio of the ultimate test load to the plastic collapse load are included. The normalised load-end rotation curves for the 12 continuous beam tests are shown in Figs 15-17. As for the simple beam tests, the arrangement of the graphs allows direct comparison between nominally similar sections from the two different production routes. A deformed continuous beam specimen (RHS $60 \times 40 \times 4-H R 1$ ), exhibiting three distinct plastic hinges (the central hinge forming first and the two hinges at the loading points forming simultaneously and precipitating collapse), is shown in Fig. 18.

\section{Analysis of Experimental Results}

\subsection{Material Properties}

From Table 1, it may be seen that the virgin material properties (from the mill certificate) and the measured material properties of the flat coupons extracted from the complete sections are 
similar. This would be expected for the hot-rolled sections, since essentially the same material is being tested. However, for the cold-formed sections, the mill test is carried out on sheet material prior to section forming, whereas the tensile coupon tests reported herein are performed on material extracted from the complete section. The limited results presented in this study indicate modest levels of strength enhancement in the flat faces of square and rectangular steel hollow sections during the cold-forming process - an average increase in strength of around $4 \%$ over the mill certificate value was observed. It would be anticipated that stockier sections exhibit greater strength enhancements owing to the higher strain input required during forming - this has been observed in studies on cold-formed circular hollow sections [23]. In the case of cold-formed stainless steel hollow sections, more considerable strength enhancements have been observed following section forming owing to the pronounced strain hardening nature of the material $[15,19]$. The results from the corner coupon tests (Table 1) have been combined with those from Guo et al. [11], Key et al. [24], Wilkinson and Hancock [25] and Zhao and Hancock [26] and plotted in Fig. 19. The measured yield strength of the corner material $\sigma_{y, c}$ has been normalised by the yield strength of the virgin material $\sigma_{y}$,mill to indicate the level of strength enhancement due to corner forming, and plotted against the corner $\mathrm{r}_{\mathrm{i}} / \mathrm{t}$ ratio. The thickness of the test specimens ranged between about $3 \mathrm{~mm}$ and $12 \mathrm{~mm}$, while the corner radii ranged between about $2 \mathrm{~mm}$ and 20 $\mathrm{mm}$. For some of the test data [24-26], the mill certificate information was not available, and the corner yield strengths were instead normalised by the measured yield strength of the flat material taken from the corresponding sections. In Fig. 19, the test results have been categorised by their ratio of ultimate tensile strength to yield strength of the virgin material $\left(\sigma_{u, m i l l} / \sigma_{y}\right.$, mill $)$, which is indicative of the potential for cold-work, whilst curves from the predictive model given in the AISI Specification for the Design of Cold-formed Steel Structural Members $[27,28]$ are also plotted on the basis of the following equations: 


$$
\frac{\sigma_{y, c, p r e d}}{\sigma_{y, \text { mill }}}=\frac{B_{c}}{\left(r_{i} / t\right)^{m}}
$$

in which

$$
\mathrm{B}_{\mathrm{c}}=3.69 \frac{\mathrm{f}_{\mathrm{u} \text {,mill }}}{\mathrm{f}_{\mathrm{y}, \text { mill }}}-0.819\left(\frac{\mathrm{f}_{\mathrm{u} \text {,mill }}}{\mathrm{f}_{\mathrm{y}, \text { mill }}}\right)^{2}-1.79
$$

and

$$
\mathrm{m}=0.92 \frac{\mathrm{f}_{\mathrm{u}, \text { mill }}}{\mathrm{f}_{\mathrm{y}, \text { mill }}}-0.068
$$

The experimental data broadly exhibits the anticipated trends, with greater corner yield strength enhancements being observed for sections with higher ratios of $\sigma_{u}$,mill $/ \sigma_{y}$,mill and tighter corner radii. On applying Eqs (2) to (4), the mean predicted divided by measured corner strength for the 40 corner test results ( 5 from the present study and 35 from the literature $[11,24-26])$ was found to be 1.13 , with a coefficient of variation of 0.10 . Note however that the corners in cold-formed tubular sections experience a particular, two-stage strain history, arising from the fact that the sections are initially formed into a circular profile, seam welded and then subsequently pressed into their final square or rectangular shapes; this is unlike the more common single continuous operation typically applied to cold-formed open sections, such as channels and lipped channels. Based on the collated test data, revised values of the coefficients of the predictive model for the corner regions of square and rectangular hollow sections, formed in the above-described fashion are proposed, as given by Eqs (5) and (6):

$$
B_{c}=2.90 \frac{f_{u, \text { mill }}}{f_{y, \text { mill }}}-0.752\left(\frac{f_{u, \text { mill }}}{f_{y, \text { mill }}}\right)^{2}-1.09
$$

and

$$
\mathrm{m}=0.23 \frac{\mathrm{f}_{\mathrm{u}, \text { mill }}}{\mathrm{f}_{\mathrm{y}, \text { mill }}}-0.041
$$


The tests results are compared to the revised predictive model in Fig. 20. Application of the revised predictive model to the 40 corner test results provides a mean predicted divided by measured corner strength equal to unity and a coefficient of variation of 0.09 .

\subsection{Geometric Imperfections}

The maximum imperfection amplitude (deviation from flatness) $\omega_{0}$ was determined for each surface profile from the twenty specimens. This was then normalised by the material thickness and plotted against $\left(\sigma_{\mathrm{y}} / \sigma_{\mathrm{cr}}\right)^{0.5}$ and $\sigma_{\mathrm{y}} / \sigma_{\mathrm{cr}}$ in order to determine the values of coefficients $\beta$ and $\gamma$ in the predictive models (Eqs. (7) and (8)) proposed by Dawson and Walker [29]. Values for the material yield stress $\sigma_{\mathrm{y}}$ and elastic critical buckling stress $\sigma_{\mathrm{cr}}$ were determined on the basis of measured geometry and measured material properties from the tensile coupon tests. The elastic buckling stress $\sigma_{\mathrm{cr}}$ was calculated based on the flat width $\mathrm{b}$ of the section faces, determined as $\mathrm{b}=\mathrm{B}-2 \mathrm{t}-2 \mathrm{r}$, where symbols are defined in Fig. 1 . Note that this definition of element width is used throughout the present paper, including in the determination of element slenderness; although alternative definitions exist from previous studies and various design codes (e.g. width measured to centreline of adjacent elements), the influence on the conclusions drawn are generally minimal.

$$
\begin{aligned}
& \omega_{0} / \mathrm{t}=\beta\left(\sigma_{\mathrm{y}} / \sigma_{\mathrm{cr}}\right)^{0.5} \\
& \omega_{0} / \mathrm{t}=\gamma\left(\sigma_{\mathrm{y}} / \sigma_{\mathrm{cr}}\right)
\end{aligned}
$$

From least-squared regression, the following values were determined for the coefficients: $\beta=$ 0.028 and $\gamma=0.064$ for hot-rolled sections and $\beta=0.034$ and $\gamma=0.068$ for cold-formed sections, indicating marginally higher imperfections in the cold-formed sections. The correlations between $\omega_{\mathrm{o}} / \mathrm{t}$ and $\left(\sigma_{\mathrm{y}} / \sigma_{\mathrm{cr}}\right)^{0.5}$ and $\omega_{\mathrm{o}} / \mathrm{t}$ and $\left(\sigma_{\mathrm{y}} / \sigma_{\mathrm{cr}}\right)$ for the determination of $\beta$ and $\gamma$ are shown in Figs. 21 and 22, respectively. The results reveal that Eq. (7) provides a better prediction (higher coefficient of determination $\mathrm{R}^{2}$ ) of the measured imperfections than Eq. 
(8). Higher values of the coefficients $(\beta=\gamma=0.2)$ were proposed by Dawson and Walker

[29] for cold-formed steel sections, but these were not based on direct measurements but rather, emerged indirectly from consideration of the imperfections required to relate resistance functions to tests, where other influences are clearly present. On the basis of imperfection measurements on structural stainless steel members, values of $\gamma$ equal to 0.044 , 0.012 and 0.008 were obtained for hot-rolled, cold-rolled and press-braked sections, respectively [17], implying lower imperfections amplitudes than observed in the present study. This perhaps reflects the tighter controls and greater emphasis placed on surface flatness and appearance in stainless steel components.

\subsection{Residual Stresses}

Residual stress magnitudes were predicted on the basis of the acquired surface residual strain measurements. Two possible initial stress distributions were considered, since the true through-thickness distribution cannot be ascertained from surface strain measurements alone - a linearly varying through-thickness distribution and a rectangular stress block distribution. Strain measurements recorded from the hot-rolled strips were very small, indicating that the bending residual stresses for hot-rolled sections were, as expected, negligible. For the coldformed box sections, the bending residual stresses showed a consistent tendency of tension on the outer surface and compression on the inner surface of the sections. The bending residual stresses released from the sectioned material have been normalised by the corresponding $0.2 \%$ proof strength and are summarised in Table 7 , where $\sigma_{\mathrm{bl}}$ refers to the linearly varying distribution and $\sigma_{b r}$ to the rectangular stress block distribution. For the flat strips, the difference in stress magnitude for the two distributions is a factor of 1.5 , this being the shape factor for a rectangular element. For the corner regions, the plastic and elastic moduli were calculated for each individual specimen. 
The mean value of the normalised bending residual stresses for the flat faces of the coldformed box sections was found to be slightly higher than that of the corner regions. Similar patterns were observed for cold-rolled steel channel sections [8] and cold-formed stainless steel box sections [18]. The bending residual stresses magnitudes for both the flat faces and corner regions of the tested box sections are generally greater than those observed in steel channel sections [8], but this would be anticipated since springback (and the resulting release of residual stresses) is effectively restricted in the production of tubes.

\subsection{Compression test results}

The results from the 20 stub column tests described herein were combined with those from other studies [16, 30-35] to assess the Class 3 slenderness limit specified in Eurocode 3 [22]. In total, 10 hot-rolled sections, 42 cold-rolled sections, 25 sections formed from plates welded at the four corners and 24 press-formed and seam welded sections were examined. The ultimate loads attained from the stub column tests were normalised by the section yield load (calculated as the product of the measured tensile yield strength $\sigma_{\mathrm{y}}$ and the gross crosssectional area A) and plotted against plate slenderness $b / t \varepsilon$, where $\varepsilon=\left(235 / \sigma_{y}\right)^{0.5}$. Note that $b$ is the flat width of the most slender element in the cross-section, as defined in Section 3.2. The results, shown in Fig. 23, indicate that attainment of the yield load is dependent on the method of forming, and that the current Class 3 limit of $42 \varepsilon$ given in Eurocode 3, assessed on the basis of compression tests, may be optimistic, though further test data, particularly for hot-rolled sections are required. This limit is also assessed on the basis of bending tests in the following section. 


\subsection{Bending test results}

The results from the simple bending tests carried out in the present study have been combined with those from existing studies [26, 35-37] on square and rectangular hollow sections and plotted in Figs 24-26. In each of these figures, the slenderness of the compression flange of the beam $b / t \varepsilon$ is plotted on the horizontal axis. For all presented data points, the compression flange is the most slender element in the section, having taken due account of the different stress distributions that exist in the flange and web through the buckling coefficient $\mathrm{k}_{\sigma}[38]$. In Fig. 24, the maximum moment achieved in the tests normalised by the elastic moment capacity $\mathrm{Mel}_{\mathrm{el}}$ is plotted on the vertical axis, allowing assessment of the Class 3 slenderness limit. The results indicate that the current slenderness limit of $42 \varepsilon$ given in Eurocode 3 is suitable for both hot-rolled and cold-formed sections, though a wider range of data is required for hot-rolled sections; this is in contrast the findings of the stub column tests, though more favourable performance would be anticipated from the bending tests due to the less onerous stress distribution in the web and therefore additional support offered to the compression flange and possible partial plastification of the tension flange. Similar findings have been observed for structural stainless steel sections [21]. In Fig. 25, the ultimate test moment has been normalised the plastic moment resistance $\mathrm{M}_{\mathrm{pl}}$ in order to assess the Class 2 slenderness limit of $38 \varepsilon$. As for the Class 3 limit, the general trend of the test data indicates that the current Class 2 slenderness limit is appropriate. Rotation capacity is examined in Fig. 26 in order to assess the Class 1 slenderness limit; the rotation capacity requirement for a Class 1 section in Eurocode 3 is that $\mathrm{R}>3$, though some design codes require $\mathrm{R}>4$. The data is somewhat scattered, as is often the case when considering rotation capacity, and there are a number of test specimens that meet the current codified requirement for a Class 1 section (i.e. $\mathrm{b} / \mathrm{t}<33 \varepsilon$ ), but show a rotation capacity of less than 3 . Further investigation is required on this matter. 
By considering test series on RHS beams that include sections where the web is the most slender element in the section, further data can be studied. A total of 65 test results are plotted in Fig. 27, 6 from the present study and the remaining results from the literature [25, 36, 37]. On the vertical axis, the maximum attained test moment has been normalised by the elastic moment capacity $\mathrm{Mel}_{\mathrm{el}}$, whilst the non-dimensional plate slenderness $\bar{\lambda}_{\mathrm{p}}=\left(\sigma_{\mathrm{y}} / \sigma_{\mathrm{cr}}\right)^{1 / 2}$ of the most slender element in the cross-section, taking due account of the different stress distributions that exist in the flange and web through the buckling coefficient $\mathrm{k}_{\sigma}[38]$ is plotted on the horizontal axis. The data display a continuous trend of increasing normalised moment capacity with reducing plate slenderness and show that moment resistance well in excess of the plastic moment capacity can be achieved. A similar trend may be seen in the results of the continuous beam tests performed in the current study, which are presented in Fig. 28. The results show that both hot-rolled and cold-formed sections can achieve ultimate loads markedly higher than the theoretical plastic collapse loads.

\subsection{Discussion}

On the basis of the results generated in the present study, together with those collected from existing studies, a number of differences between the behaviour of hot-rolled and coldformed hollow sections have been observed. It is generally observed that the current slenderness limits and plastic design approaches are equally applicable to hot-rolled and coldformed sections, though the results of the stub column tests indicate a dependency on forming route and question the current Class 3 slenderness limit. Of the various features investigated, it is concluded that the strain hardening characteristics represent the most influential factor in shaping the individual structural responses of hot-rolled and cold-formed sections, particularly for non-slender sections. The inability of existing codes to rationally exploit the 
strain hardening of the material is evident, with stocky sections achieving load-carrying capacities significantly beyond those predicted by current design approaches. A new design approach, the continuous strength method (CSM) [39, 40], has been developed to overcome these shortcomings, offering a systematic means of utilising strain hardening, based on crosssection deformation capacity.

\section{Conclusions}

A series of tests on hot-rolled and cold-formed steel hollow sections has been performed in order to assess the influence of the two different production routes on material and structural responses. Material tests revealed modest increases in strength in the flat regions of coldformed sections during forming, but marked strength enhancements in the corner regions; these were compared with the AISI predictive model and revised coefficients have been proposed. Geometric imperfections were found to be of similar magnitude in the two section types, while high bending residual stresses were observed in the cold-formed sections. Current codified slenderness limits were evaluated on the basis of compressive and bending tests on hot-rolled and cold-formed sections. The results revealed that current limits are generally acceptable for both production routes, though the suitability of the Class 3 (yield) slenderness limit was found to be dependant upon the means of evaluation. With the requirement of reaching the yield load in compression for a section to be Class 3 , the stub column test results indicate that the limit may be production route-dependant and rather optimistic, though evaluation of the same limit on the basis of attaining the yield moment in bending tests indicates that the current limit is satisfactory. Further test data, particularly for hot-rolled sections, are required to confirm this point. The results of continuous beam tests showed that plastic design was equally applicable to stocky hot-rolled and cold-formed 
sections. A feature of many of the tests was the pronounced over-strength in comparison to current design guidance as a result of strain hardening; a new design approach, the continuous strength method (CSM), is under development to address this issue.

\section{Acknowledgements}

The authors would like to acknowledge Gordon Herbert, Nikolaos Margaritis, Ka Ho Nip and Tak Ming Chan for providing assistance during the various experimental investigations.

\section{References}

[1] EN 10210-1. Hot-finished structural hollow sections of non-alloy and fine grain steels, European Standard, CEN, 2006.

[2] Whitfield, S. Hot v. cold formed hollow sections, The Structural Engineer, 2007; 85(21), 32 and 34.

[3] EN 10219-2. Cold-formed welded structural hollow sections of non-alloy and fine grain steels, European Standard, CEN, 2006.

[4] Zhao, X. L., Wilkinson, T. J. and Hancock, G. J. Cold-formed tubular members and connections. Elsevier, Oxford, 2005.

[5] Madugula, M. K. S., Haidur, R., Monforton, G. R. and Marshall, D. G. Additional residual stress and yield stress tests on hot-rolled angles. Proceedings of the Structural 
Stability Research Council Annual Technical Session. June 1997, Toronto, Canada. pp. 55-68. 1997.

[6] Lay, M. G., and Ward, R. Residual stresses in steel sections. Journal of the Australian Institute of Steel Construction, 1969; 3(3), 2-21.

[7] Chan, T. M. and Gardner, L. Compressive resistance of hot-rolled elliptical hollow sections. Engineering Structures, 2008; 30(2), 522-532.

[8] Schafer B. W. and Peköz T., Computational modeling of cold-formed steel: characterizing geometric imperfections and residual stresses, Journal of Constructional Steel Research, 1998; 47(3), 193-210.

[9] Chou S. M., Chai G. B. and Ling L., Finite element technique for design of stub columns, Thin-Walled Structures, 2000; 37(2), 97-112.

[10] Dubina D. and Ungureanu V., Effect of imperfections on numerical simulation of instability behaviour of cold-formed steel members, Thin-Walled Structures, 2002; 40(3), 239-262.

[11] Guo Y.-J., Zhu A.-Z., Pi Y.-L. and Tin-Loi F., Experimental study on compressive strengths of thick-walled cold-formed sections, Journal of Constructional Steel Research, 2007; 63(5), 718-723. 
[12] Liu Y. and Young B., Buckling of stainless steel square hollow section compression members, Journal of Constructional Steel Research, 2003; 59(2), 165-177.

[13] Gardner L. and Nethercot D. A., Experiments on stainless steel hollow sections - Part 1: Material and cross-sectional behaviour, Journal of Constructional Steel Research, 2004; 60(9), 1291-1318.

[14] Gardner L. and Nethercot D. A., Numerical modeling of stainless steel structural components - A consistent approach, Journal of Structural Engineering, ASCE, 2004; 130(10), 1586-1601.

[15] Ashraf M., Gardner L. and Nethercot D. A., Strength enhancement of the corner regions of stainless steel cross-sections, Journal of Constructional Steel Research, 2005; 61(1), $37-52$.

[16] Akiyama, H., Kuwamura, H., Yamada, S. and Chiu, J.-C., Influences of manufacturing processes on the ultimate behaviour of box-section members, Proceedings of the Third Pacific Structural Steel Conference, Tokyo, Japan. October 26-28, 1992; 313-320. 1992.

[17] Cruise, R. B. and Gardner, L. Measurement and prediction of geometric imperfections in structural stainless steel members. Structural Engineering and Mechanics, 2006; 24(1), 63-89.

[18] Cruise, R. B. and Gardner, L. Residual stress analysis of structural stainless steel sections. Journal of Constructional Steel Research, 2008; 64(3), 352-366. 
[19] Cruise, R. B. and Gardner, L. Strength enhancements induced during cold forming of stainless steel sections. Journal of Constructional Steel Research, 2008; 64(11), 13101316.

[20] EN 10002-1. Metallic materials - Tensile testing, Part 1: Method of test at ambient temperature, European Standard, CEN, 1990.

[21] Gardner, L. and Theofanous, M. Discrete and continuous treatment of local buckling in stainless steel elements, Journal of Constructional Steel Research, 2008; 64(11), $1207-$ 1216.

[22] EN 1993-1-1. Eurocode 3: Design of steel structures - Part 1-1: General rules and rules for buildings, European Standard, CEN, 2005.

[23] Kurobane, Y., Ogawa, K. and Ochi, K. Recent research developments in the design of tubular structures, Journal of Constructional Steel Research, 1989, 13(2-3), 169-188.

[24] Key, P. W., Hasan, S. W. and Hancock, G. J. Column Behavior of Cold-Formed Hollow Sections. Journal of Structural Engineering, ASCE, 1988; 114(2), 390-407.

[25] Wilkinson, T. and Hancock, G. J. Tests for the compact web slenderness of cold-formed rectangular hollow sections. Research Report No R744. University of Sydney, 1997. 
[26] Zhao, X. L., and Hancock, G. J. (1992). Square and rectangular hollow sections subject to combined actions. Journal of Structural Engineering, ASCE, 118(3), 648-668.

[27] Specification for the Design of Cold-formed Steel Structural Members. AISI, 1996.

[28] Karren, K. W. Corner properties of cold-formed steel shapes, Journal of the Structural Division, ASCE, 1967, 93(1), 401-432.

[29] Dawson R. G. and Walker A. C., Post-buckling of geometrically imperfect plates, Journal of the Structural Division, ASCE, 1972; 98(1), 75-94.

[30] Ge, H. and Usami, T., Strength of concrete-filled thin-walled steel box columns: Experiment, Journal of Structural Engineering, 1992; 118(11), 3036-3054.

[31] Uy, B., Local and post-buckling of concrete filled steel welded box columns, Journal of Constructional Steel Research, 1998; 47(1-2), 47-72.

[32] Han, L. H., Tao, Z., Huang, H. and Zhao, X. L., Concrete-filled double skin (SHS outer and CHS inner) steel tubular beam-columns, Thin-Walled Structures, 2004; 42(9), 13291355.

[33] Tao, Z., Han, L.-H. and Wang, Z.-B., Experimental behaviour of stiffened concretefilled thin-walled hollow steel structural (HSS) stub columns, Journal of Constructional Steel Research, 2005; 61(7), 962-983. 
[34] Gao, L., Sun, H., Jin, F. and Fan, H., Load-carrying capacity of high-strength steel boxsections I: Stub columns, Journal of Constructional Steel Research; 65(4), 918-924.

[35] Hancock, G. J. and Zhao, X. L. Research into the strength of cold-formed tubular sections. Journal of Constructional Steel Research, 1992, 23(1-3), 55-72.

[36] Wilkinson, T. Hancock, G. J. Tests to examine compact web slenderness of cold-formed RHS. Journal of Structural Engineering, ASCE, 1998; 124(10), 1116-1174.

[37] Zhao, X. L and Hancock, G. J. Tests to determine plate slenderness limits for coldformed rectangular hollow sections of grade C450. Journal of the Australian Institute of Steel Construction, 1991, 25(4), 2-16.

[38] EN 1993-1-5. Eurocode 3: Design of steel structures - Part 1-5: Plated structural elements. CEN, 2005.

[39] Gardner, L. The Continuous Strength Method. Proceedings of the Institution of Civil Engineers - Structures and Buildings, 2008; 161(3), 127-133.

[40] Ashraf, M., Gardner, L. and Nethercot, D. A. Structural stainless steel design: Resistance based on deformation capacity. Journal of Structural Engineering, ASCE, 2008; 134(3), 402-411. 


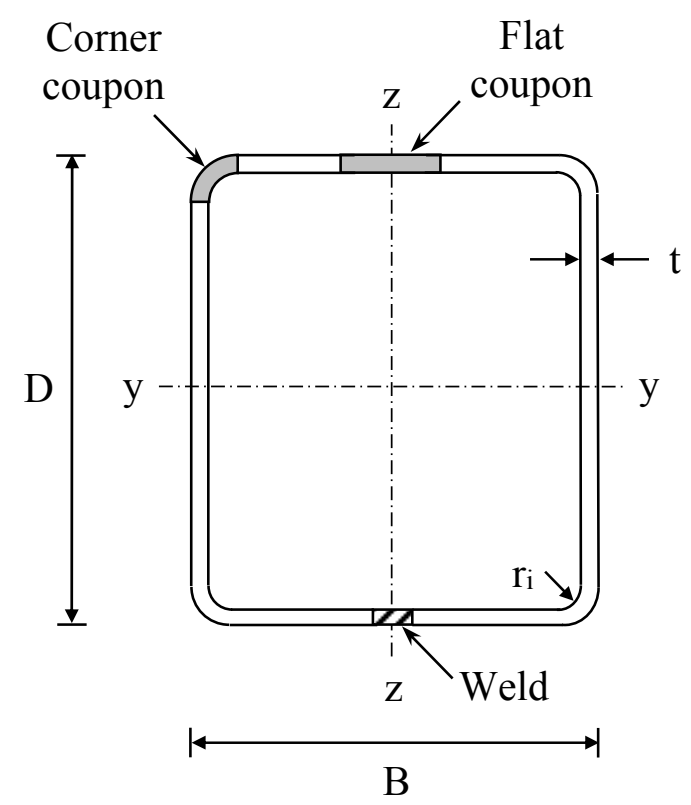

Fig. 1: Section labelling convention and location of flat and corner tensile coupons

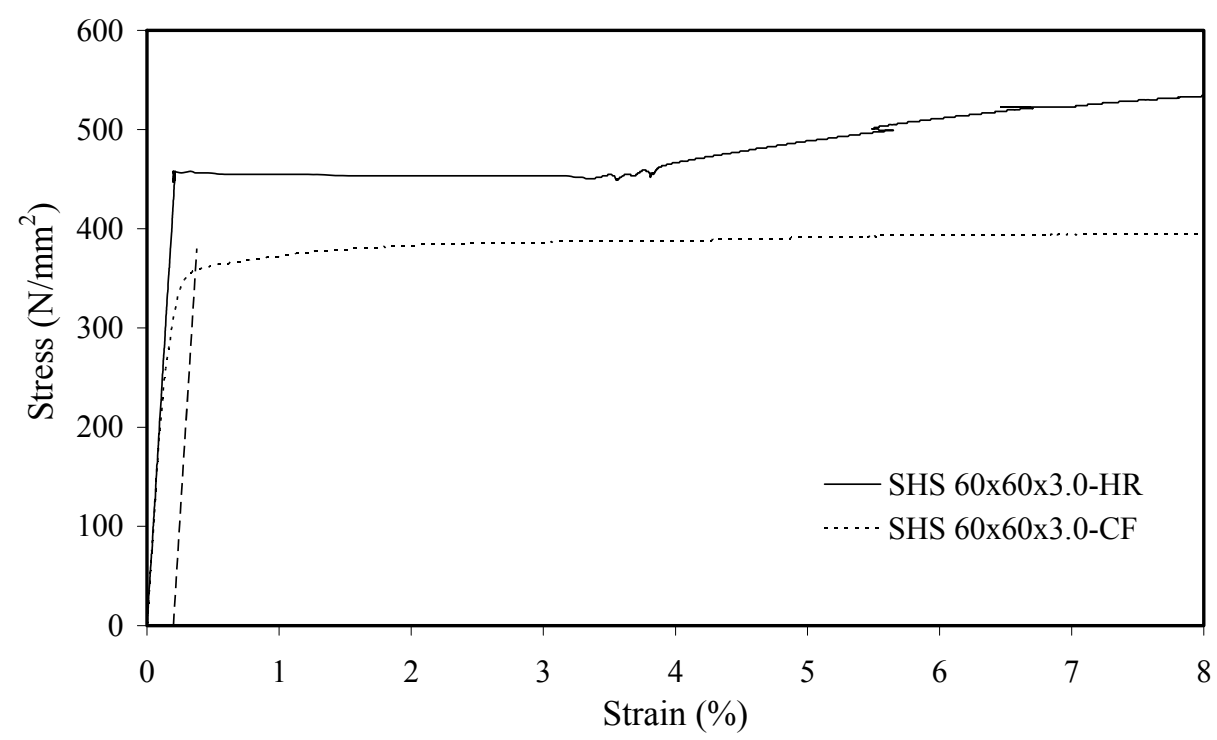

Fig. 2: Typical stress-strain curves from hot-rolled and cold-formed tensile coupons (SHS $60 \times 60 \times 3$ ) 


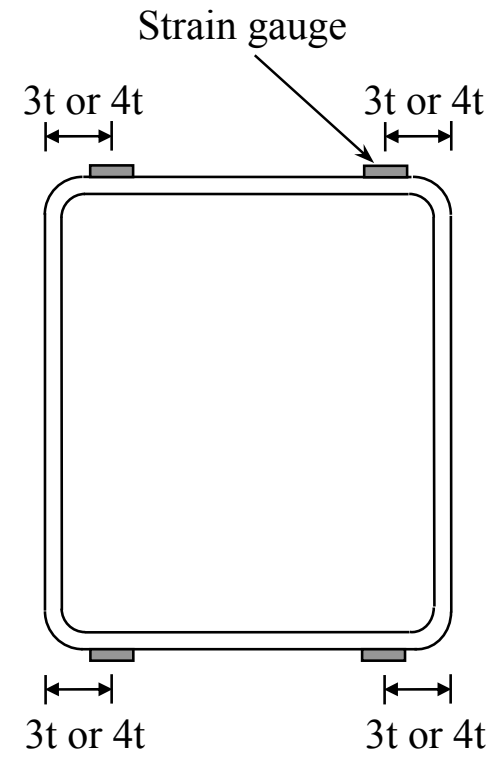

Fig. 3: Locations of strain gauges on stub column specimens

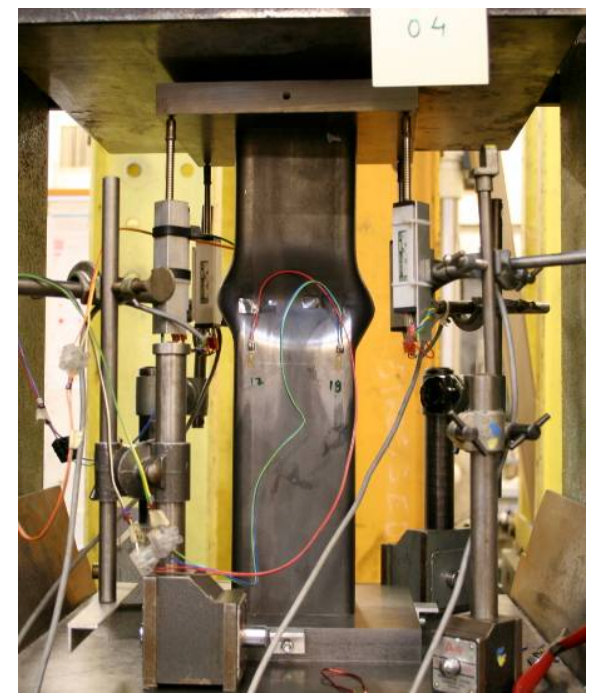

Fig. 4: General view of stub column experimental set-up 


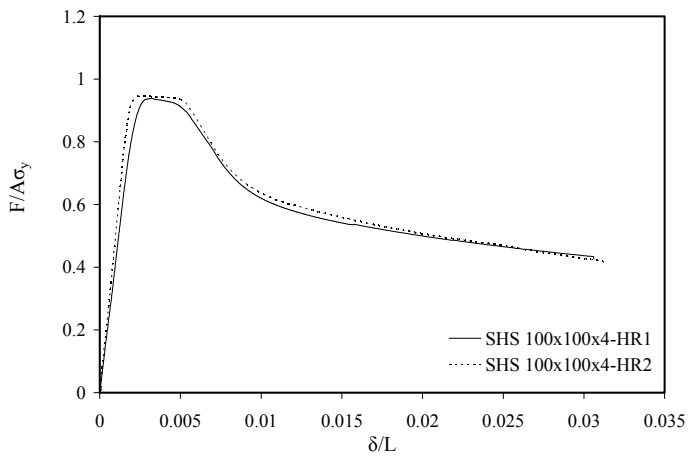

(a) Hot-rolled SHS $100 \times 100 \times 4$ stub columns

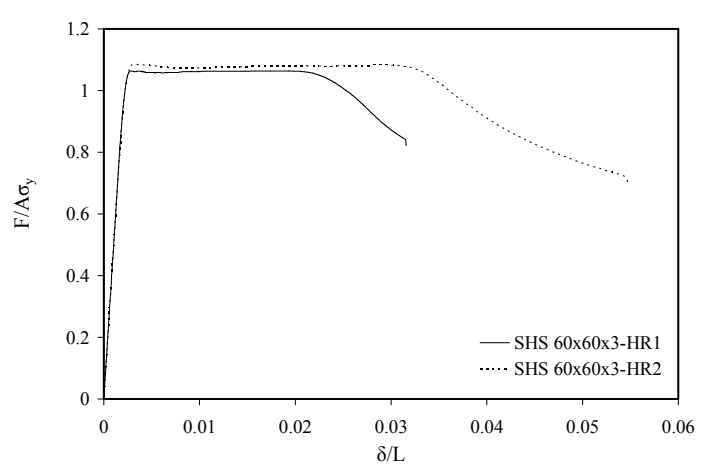

(c) Hot-rolled SHS $60 \times 60 \times 3$ stub columns

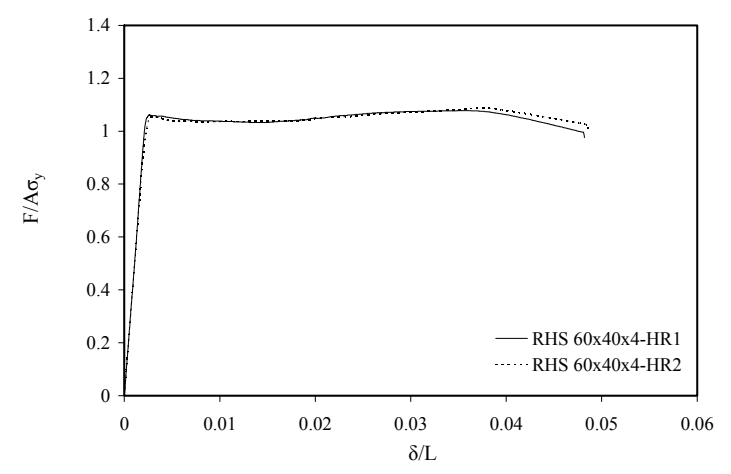

(e) Hot-rolled RHS $60 \times 40 \times 4$ stub columns

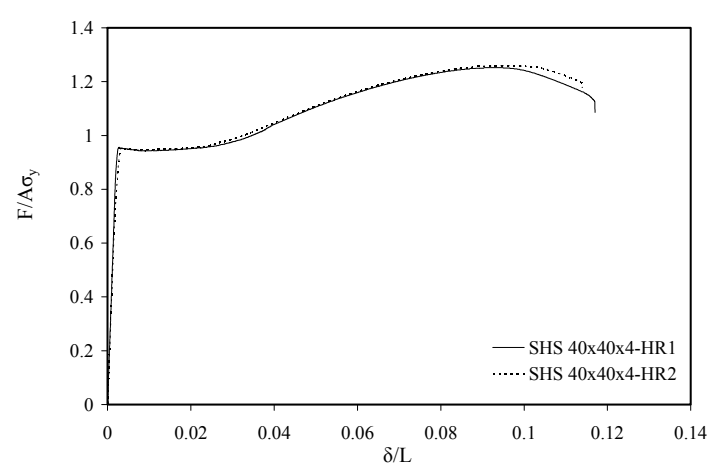

(g) Hot-rolled SHS $40 \times 40 \times 4$ stub columns

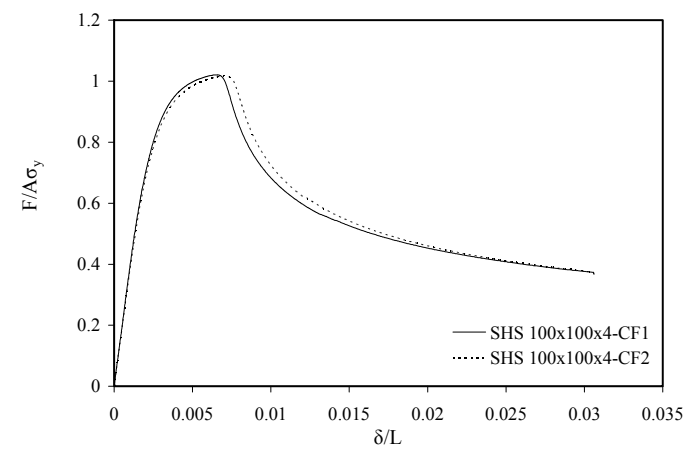

(b) Cold-formed SHS $100 \times 100 \times 4$ stub columns

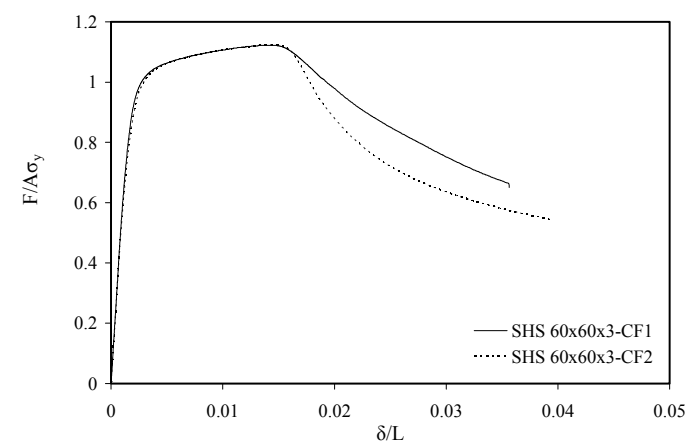

(d) Cold-formed SHS $60 \times 60 \times 3$ stub columns

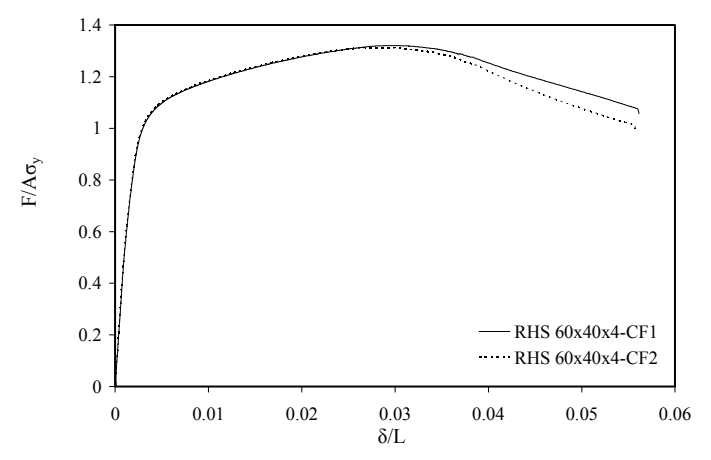

(f) Cold-formed RHS $60 \times 40 \times 4$ stub columns

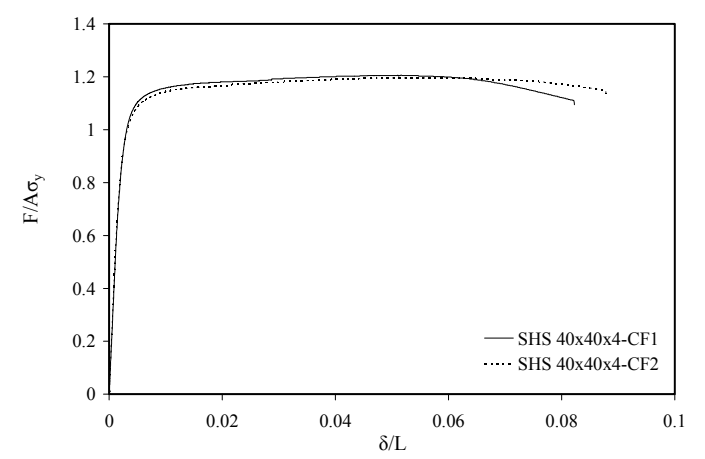

(h) Cold-formed SHS $40 \times 40 \times 4$ stub columns 


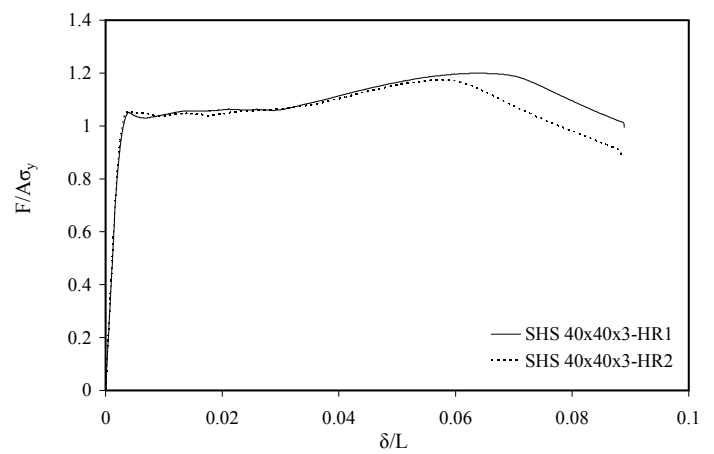

(i) Hot-rolled SHS $40 \times 40 \times 3$ stub columns

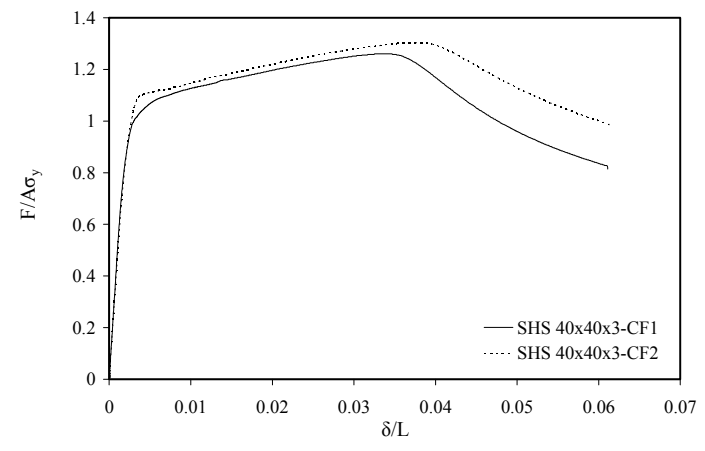

(j) Cold-formed SHS $40 \times 40 \times 3$ stub columns

Fig. 5: Normalised load-end shortening curves of tested stub columns

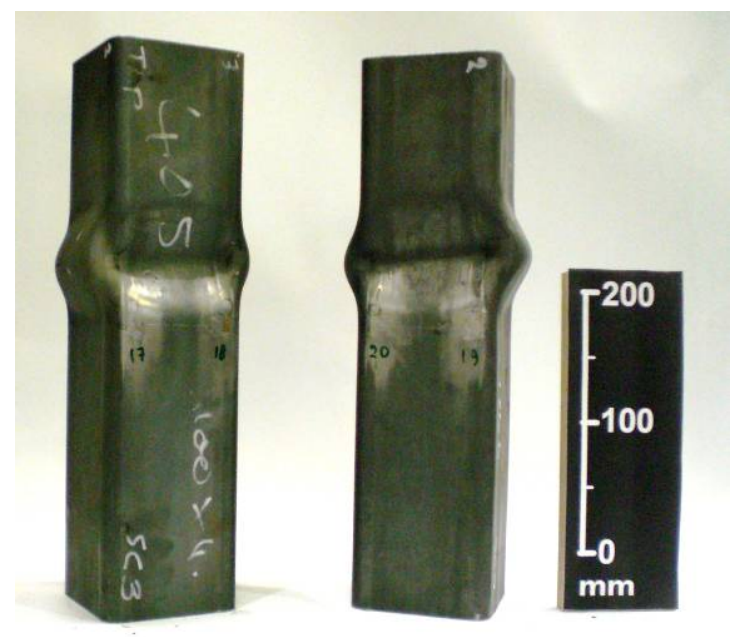

Fig. 6: Typical local buckling failure mode of stub columns (SHS 100×100×4-CF1 and CF2) 


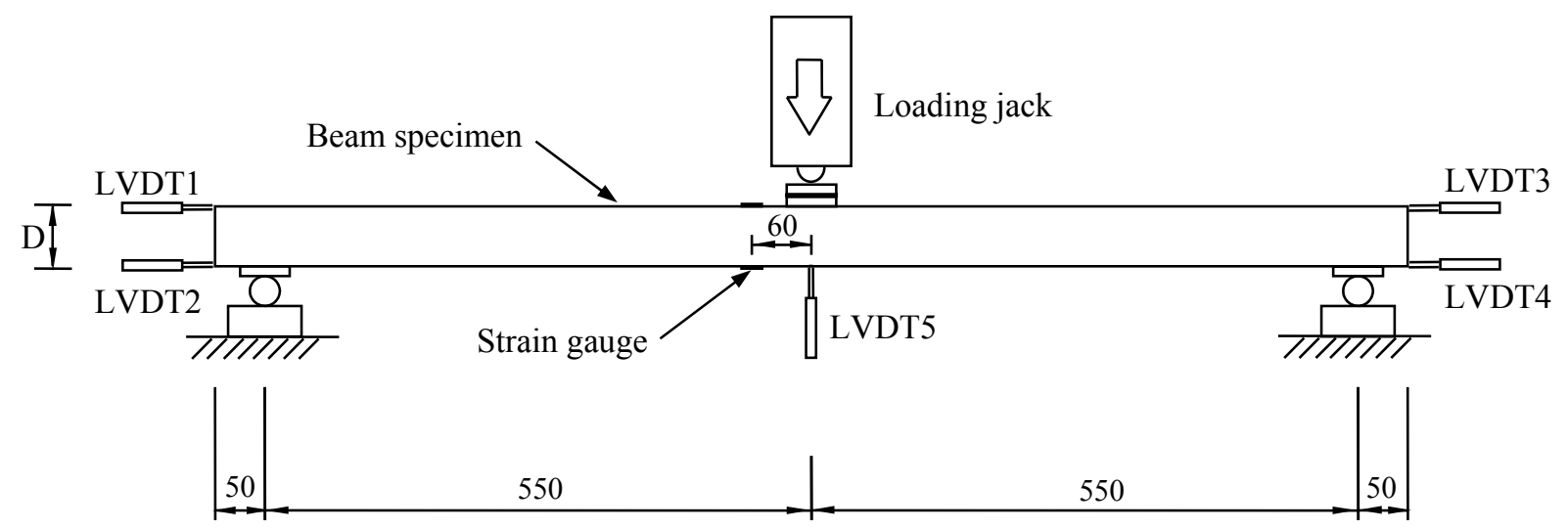

Fig. 7: Schematic three-point bending test arrangement

Applied moment M

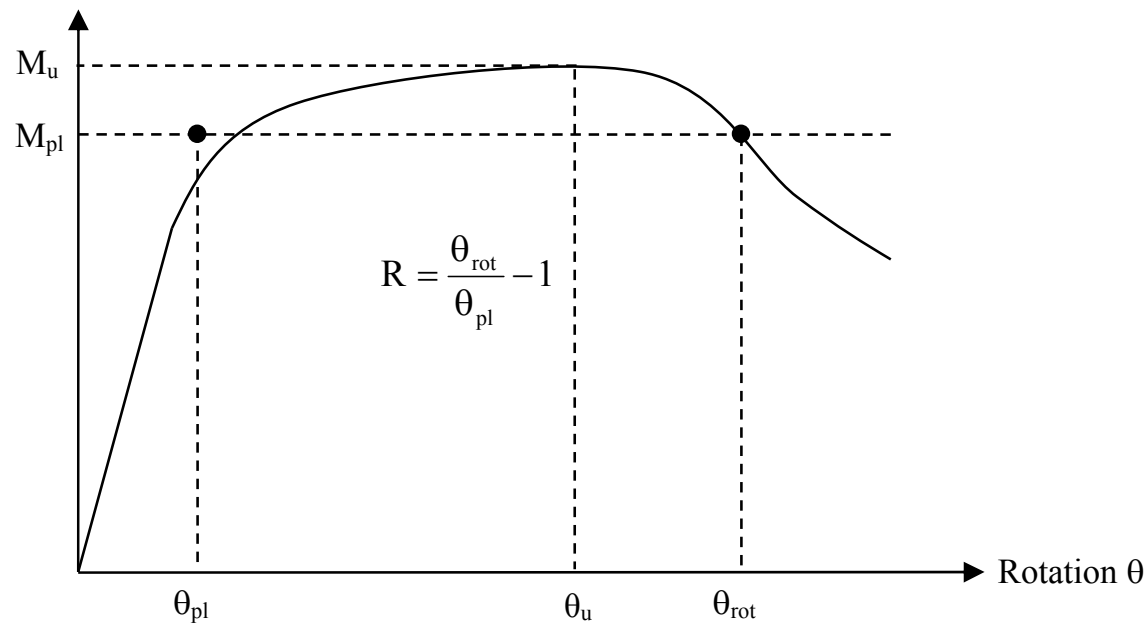

Fig. 8: Definition of rotation capacity from moment-rotation graphs 


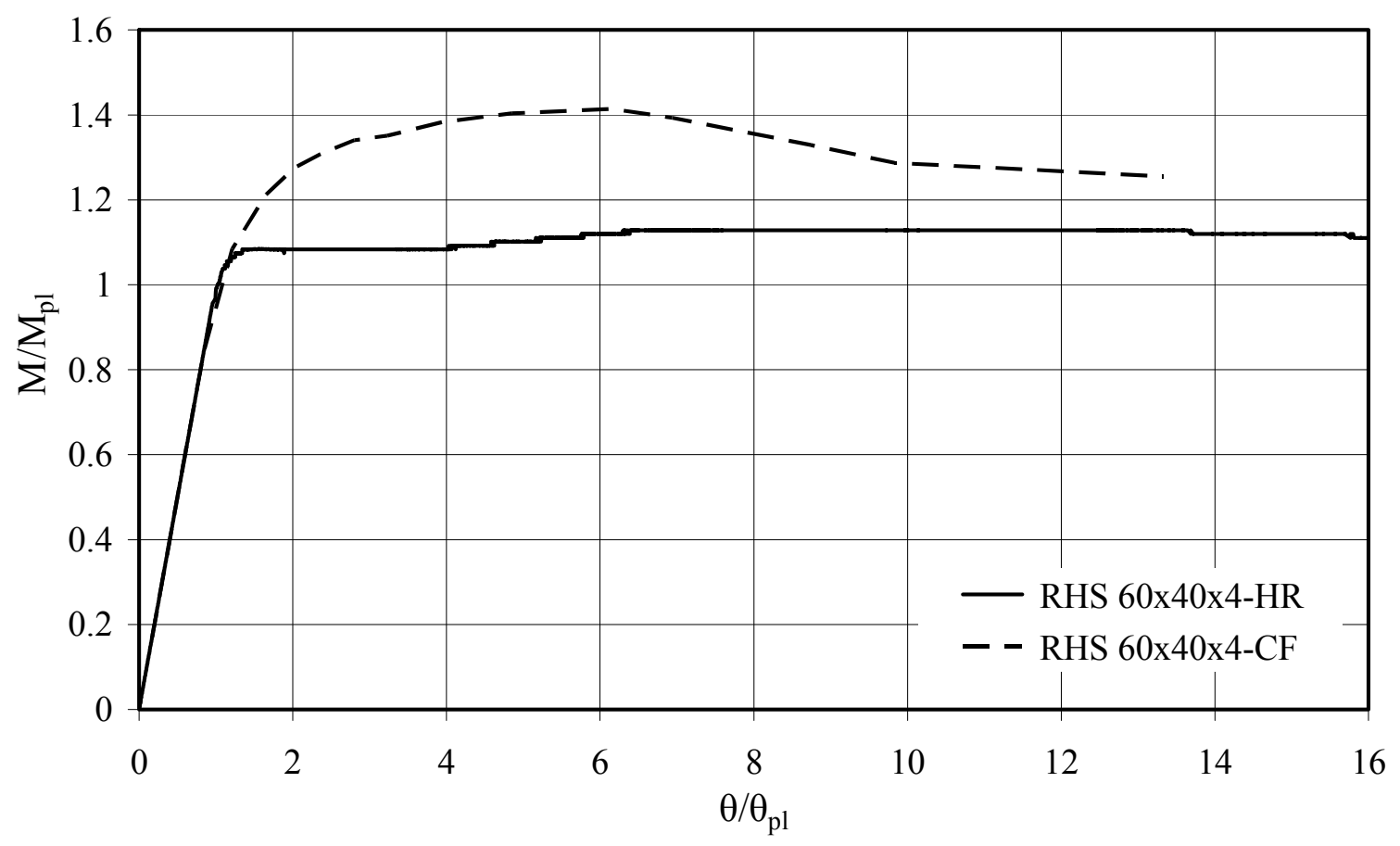

Fig. 9: Normalised moment-rotation curves for simple SHS $60 \times 40 \times 4$ beams

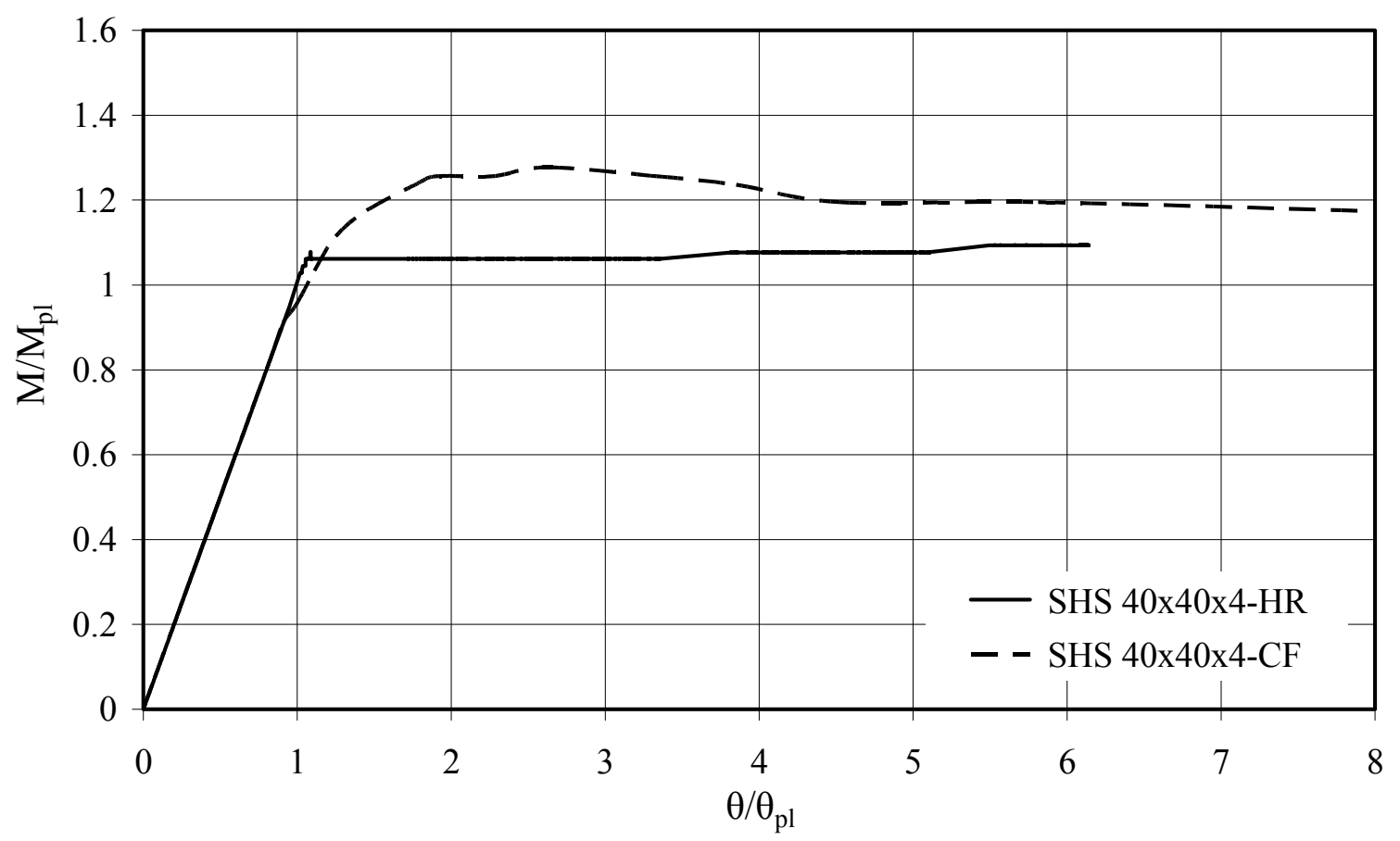

Fig. 10: Normalised moment-rotation curves for simple SHS $40 \times 40 \times 4$ beams 


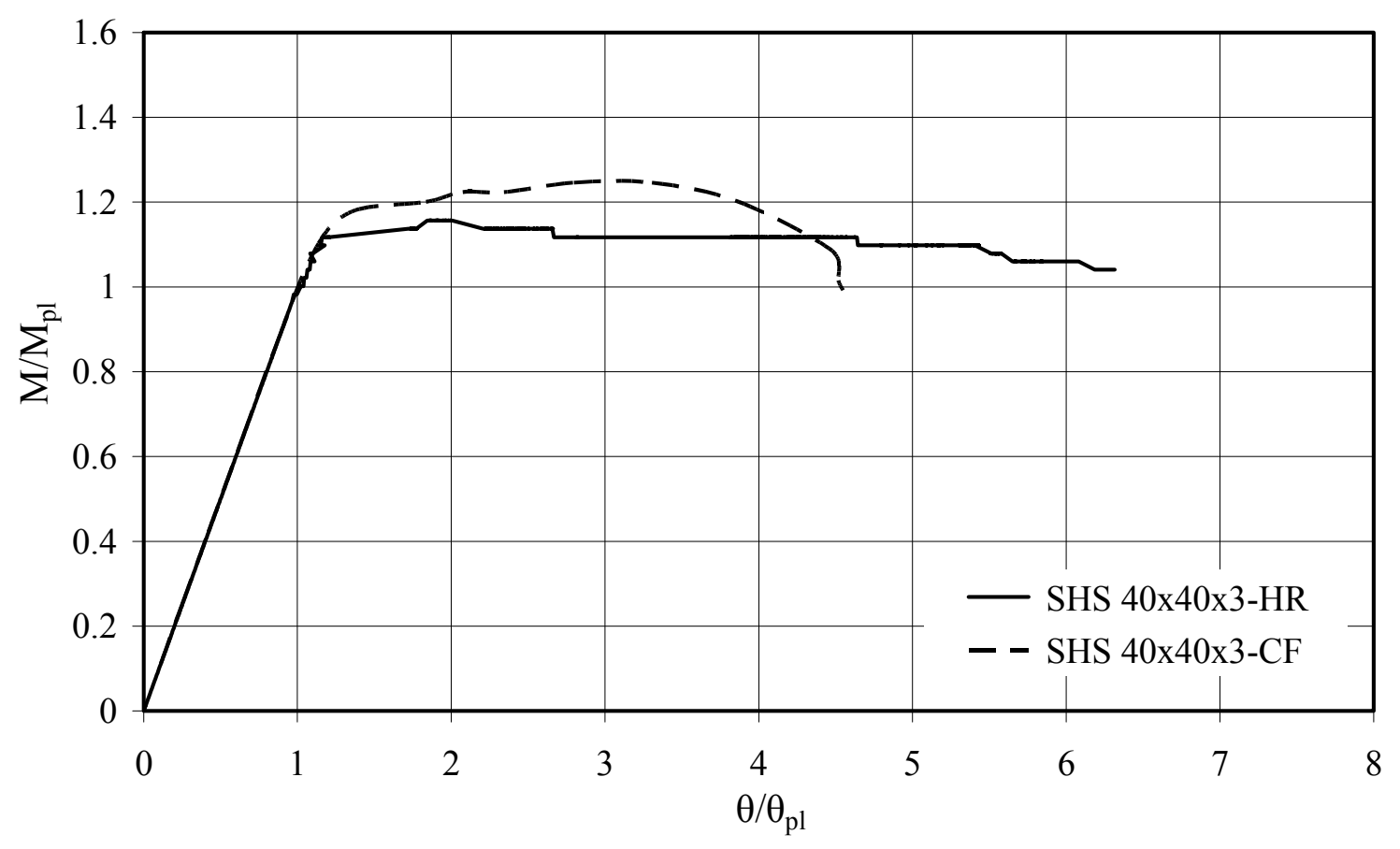

Fig. 11: Normalised moment-rotation curves for simple SHS $40 \times 40 \times 3$ beams

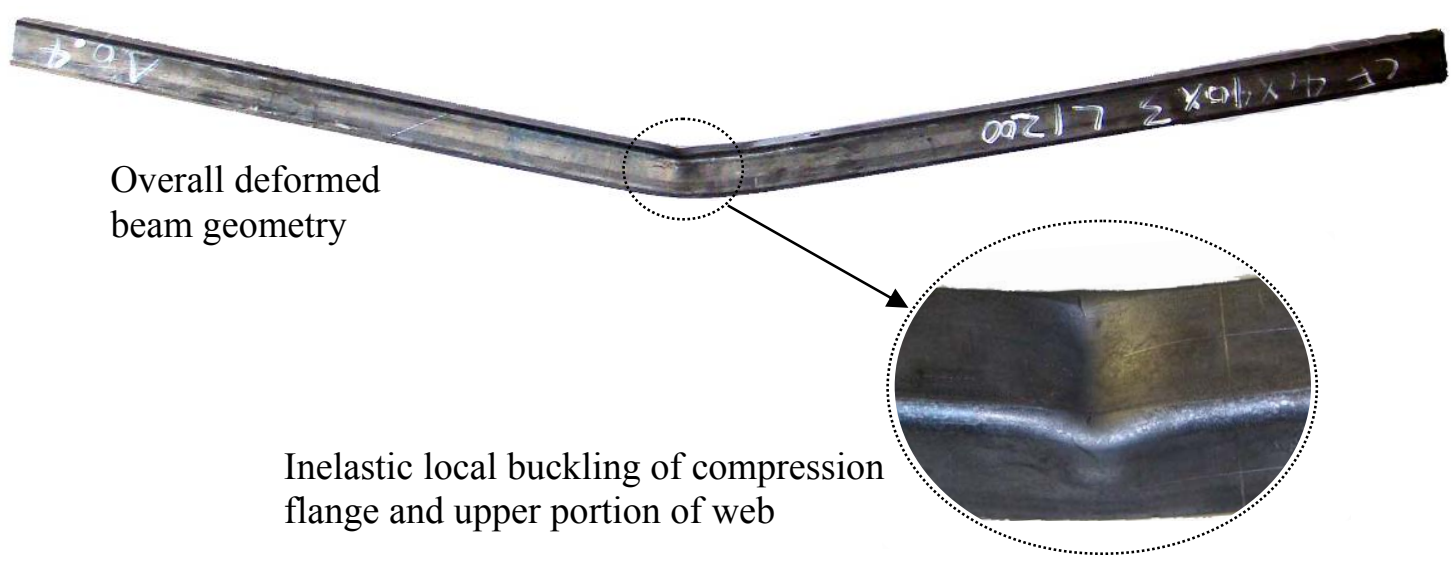

Fig. 12: A typical deformed simple beam test specimen (SHS $40 \times 40 \times 3-\mathrm{CF}$ ) 


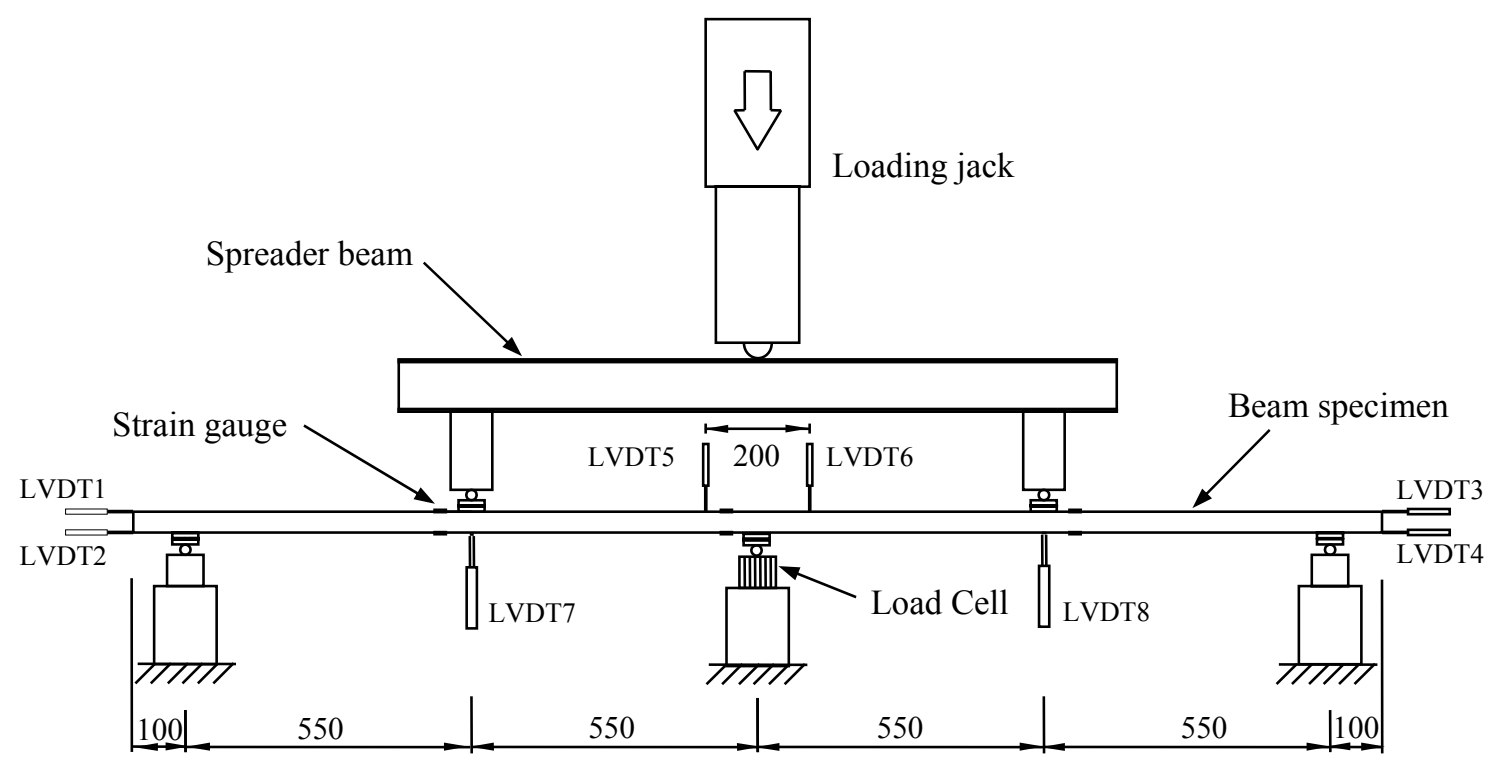

Fig. 13: Continuous beam setup 1 - loading applied centrally between supports (dimensions in $\mathrm{mm}$ )

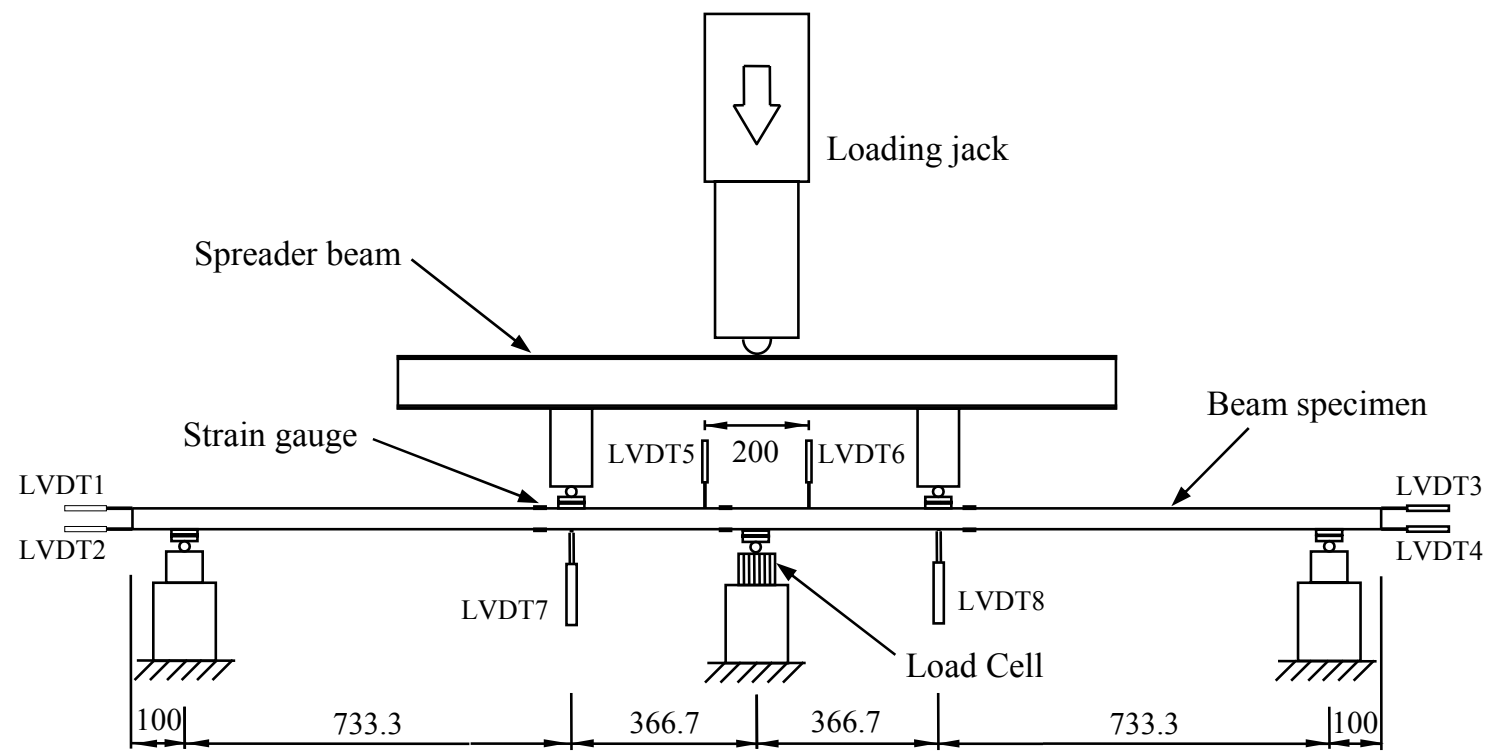

Fig. 14: Continuous beam setup 2 - loading applied at 1/3 distance between supports (dimensions in $\mathrm{mm}$ ) 


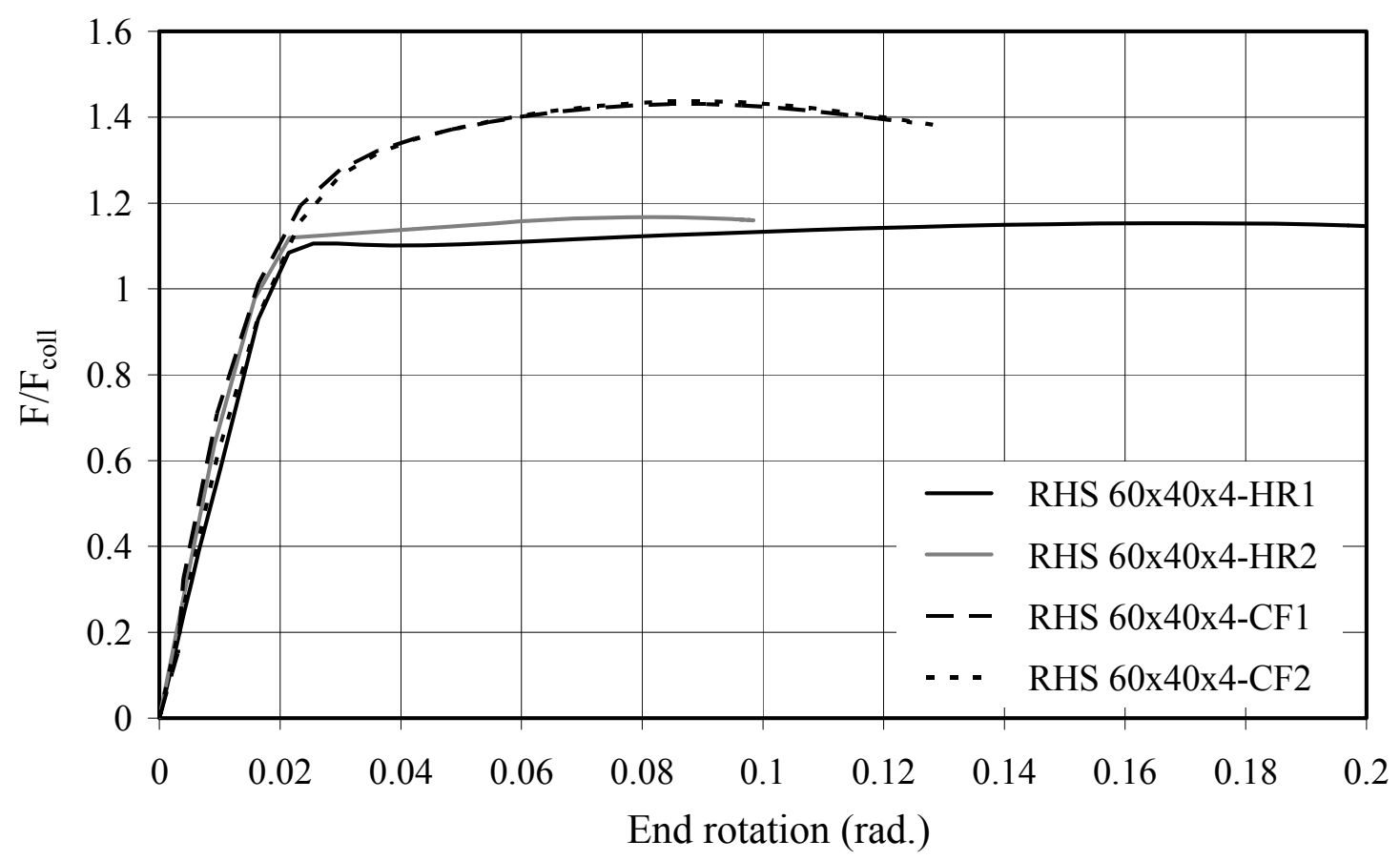

Fig. 15: Normalised load-end rotation curves for RHS $60 \times 40 \times 4$ continuous beams

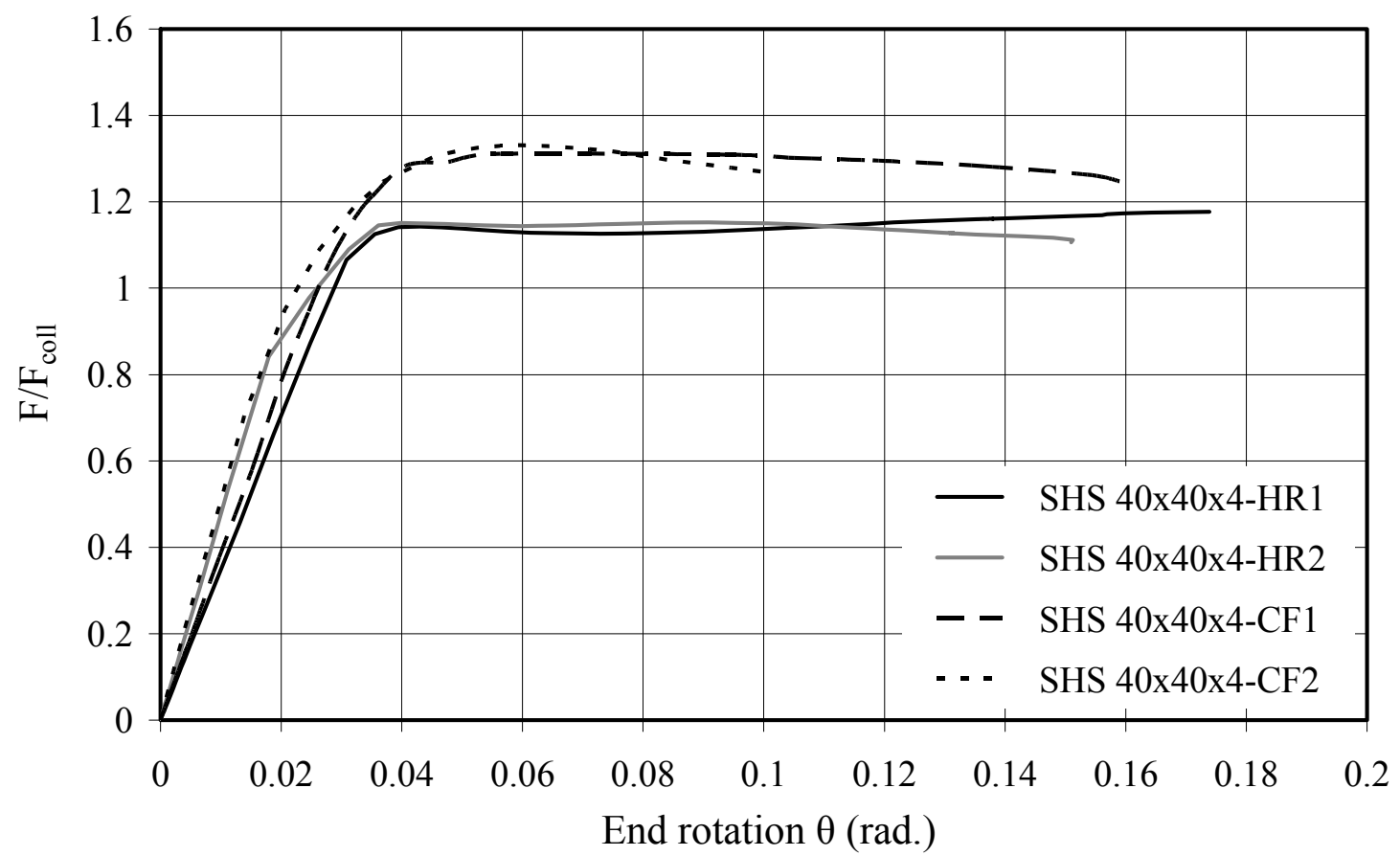

Fig. 16: Normalised load-end rotation curves for SHS $40 \times 40 \times 4$ continuous beams 


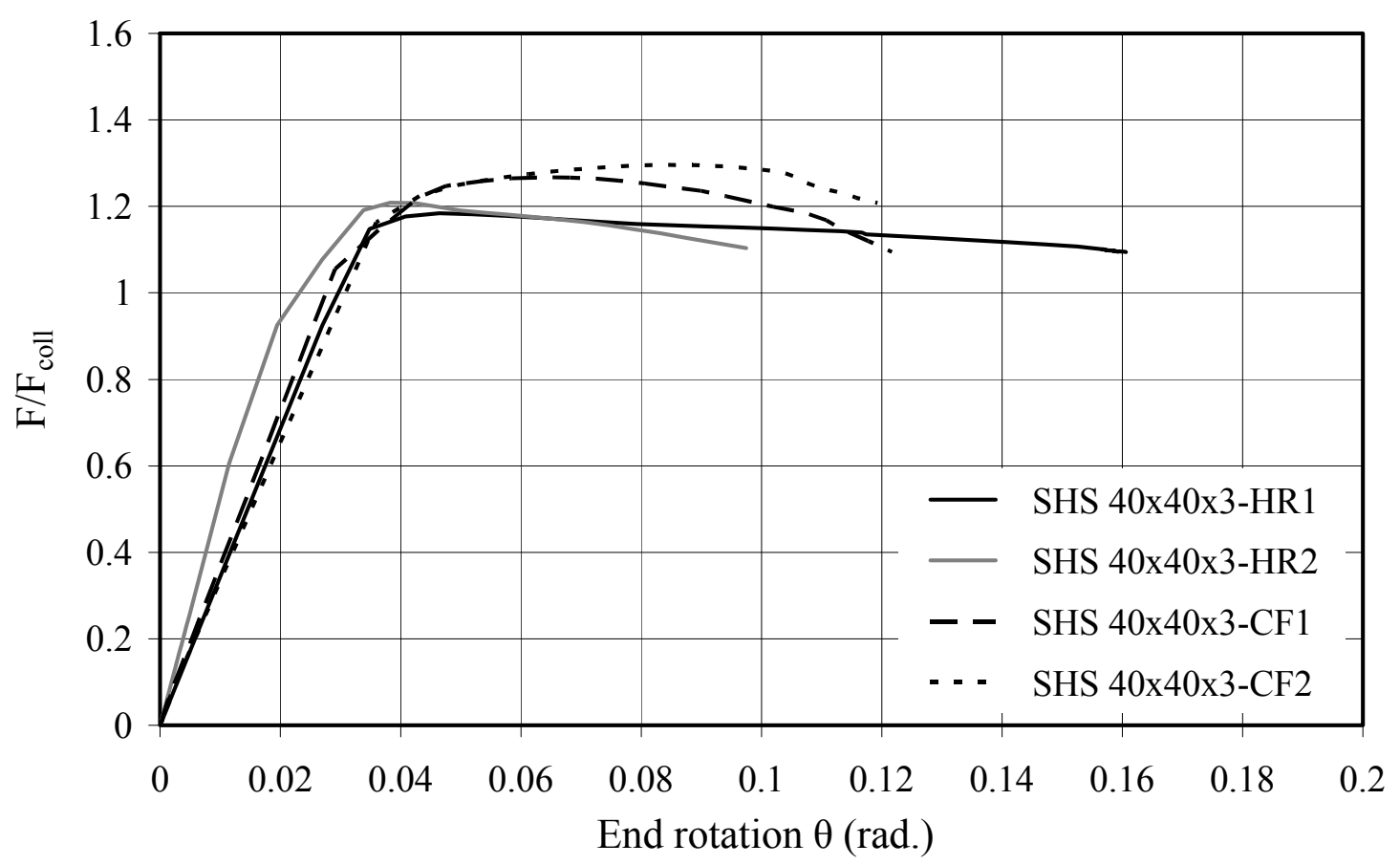

Fig. 17: Normalised load-end rotation curves for SHS $40 \times 40 \times 4$ continuous beams

Hinge 1 forms at central support

Fig.18: Location of plastic hinges in deformed continuous beam (RHS 60×40×4-HR1) 


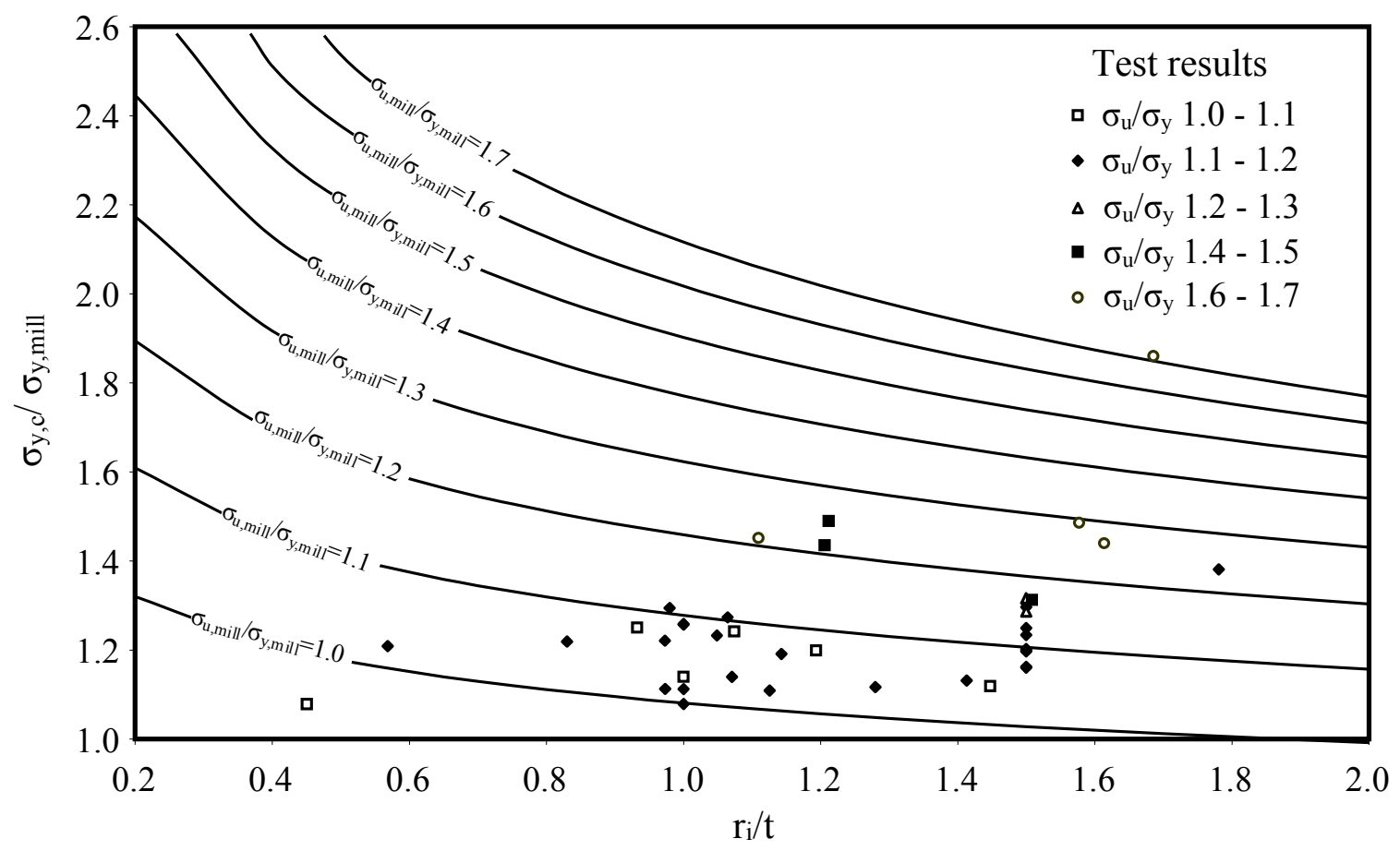

Fig. 19: Corner material strength data and AISI predictive model

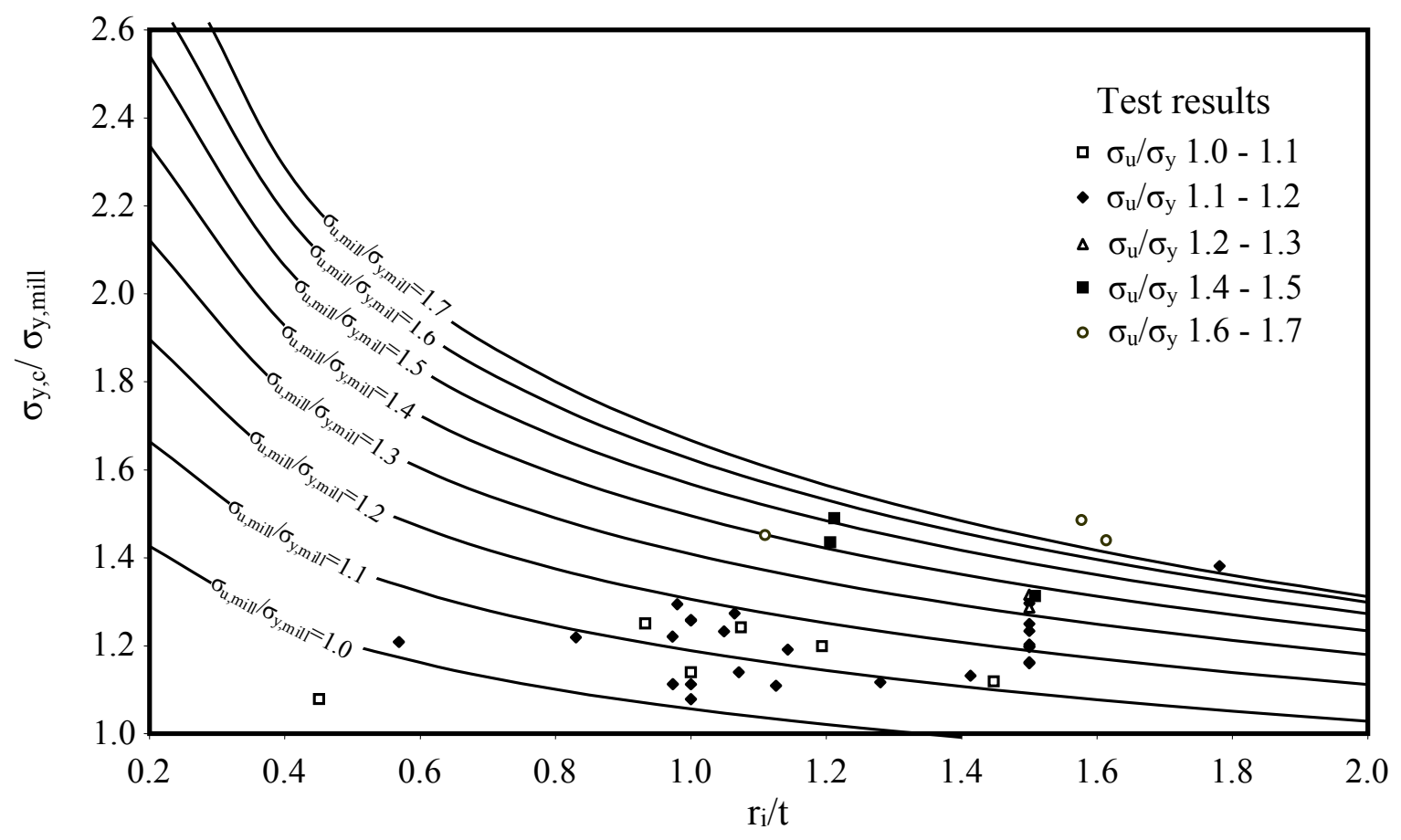

Fig. 20: Corner material strength data and revised predictive model 


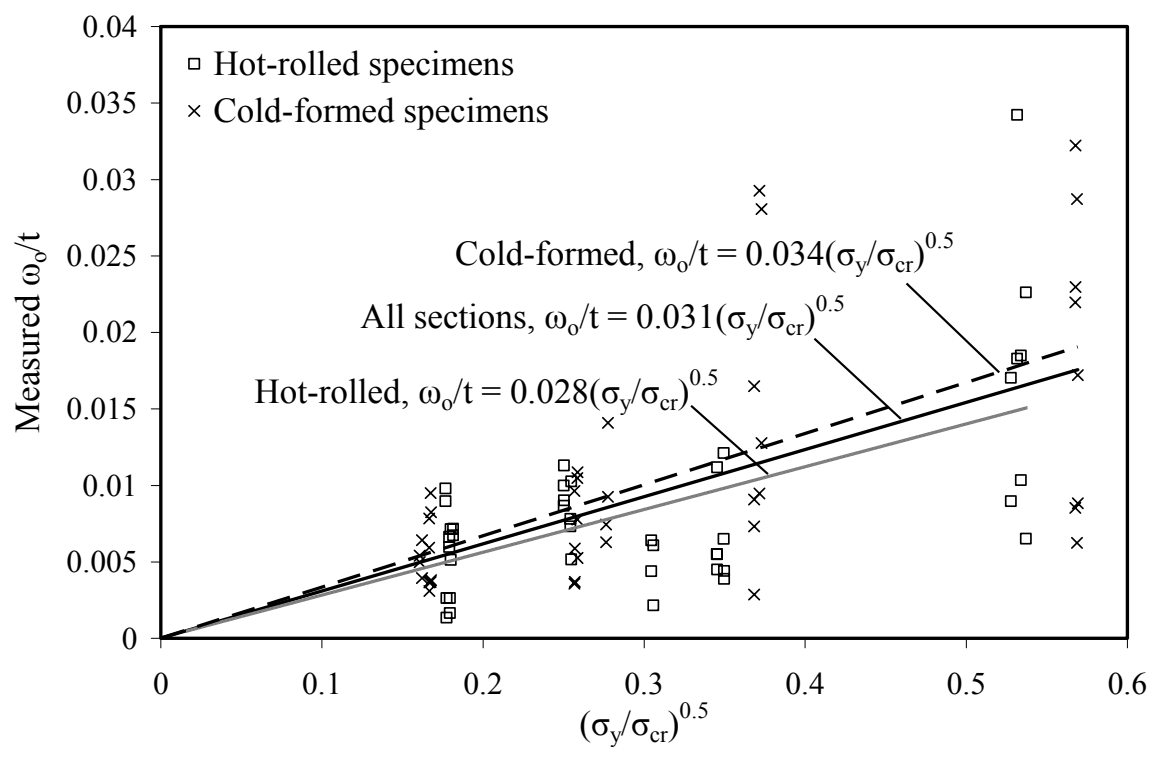

Fig. 21: Correlation between $\omega_{\mathrm{o}} / \mathrm{t}$ and $\left(\sigma_{\mathrm{y}} / \sigma_{\mathrm{cr}}\right)^{0.5}$ for the determination of $\beta$

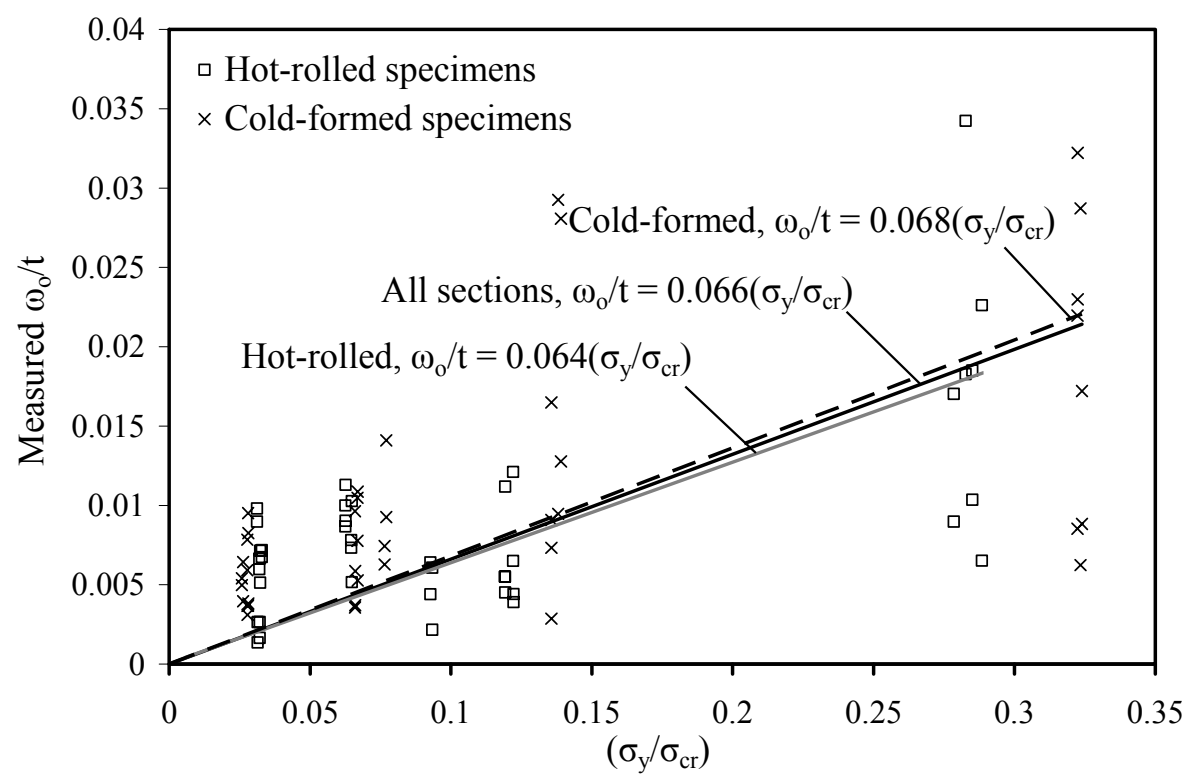

Fig. 22: Correlation between $\omega_{\mathrm{o}} / \mathrm{t}$ and $\sigma_{\mathrm{y}} / \sigma_{\mathrm{cr}}$ for the determination of $\gamma$ 


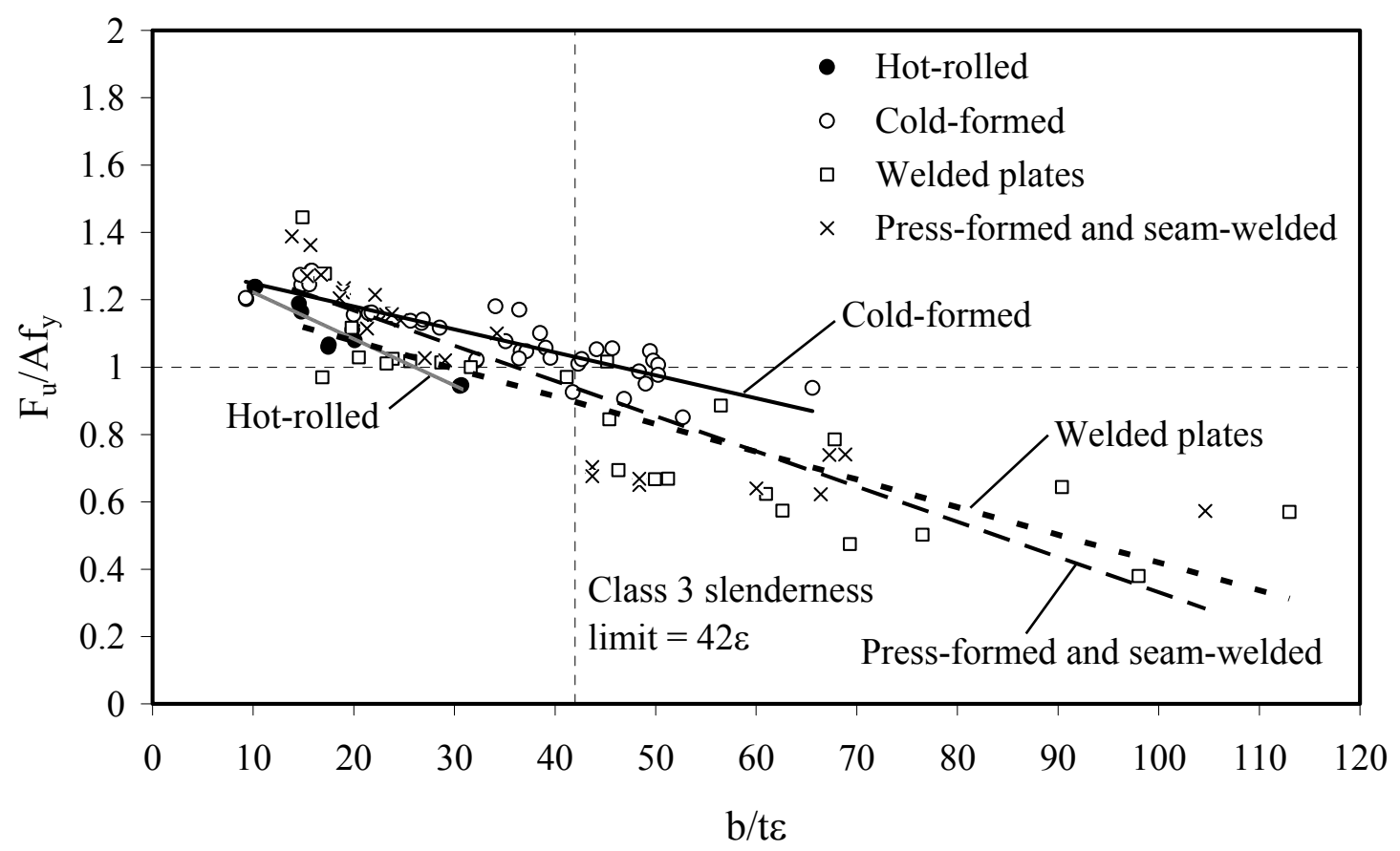

Fig. 23: Normalised stub column resistances versus plate slenderness

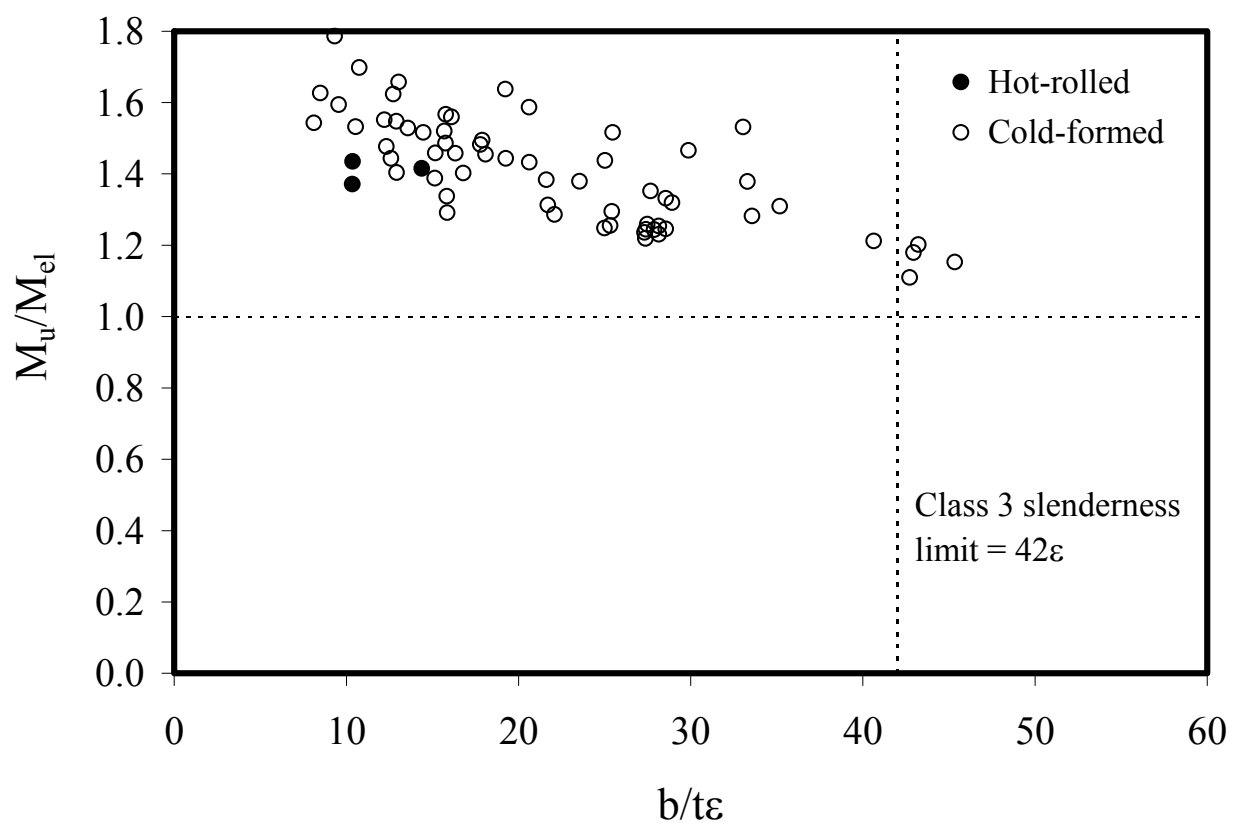

Fig. 24: $\mathrm{Mu} / \mathrm{Mel}$ versus $\mathrm{b} / \mathrm{t} \varepsilon$ for assessment of Class 3 slenderness limit 


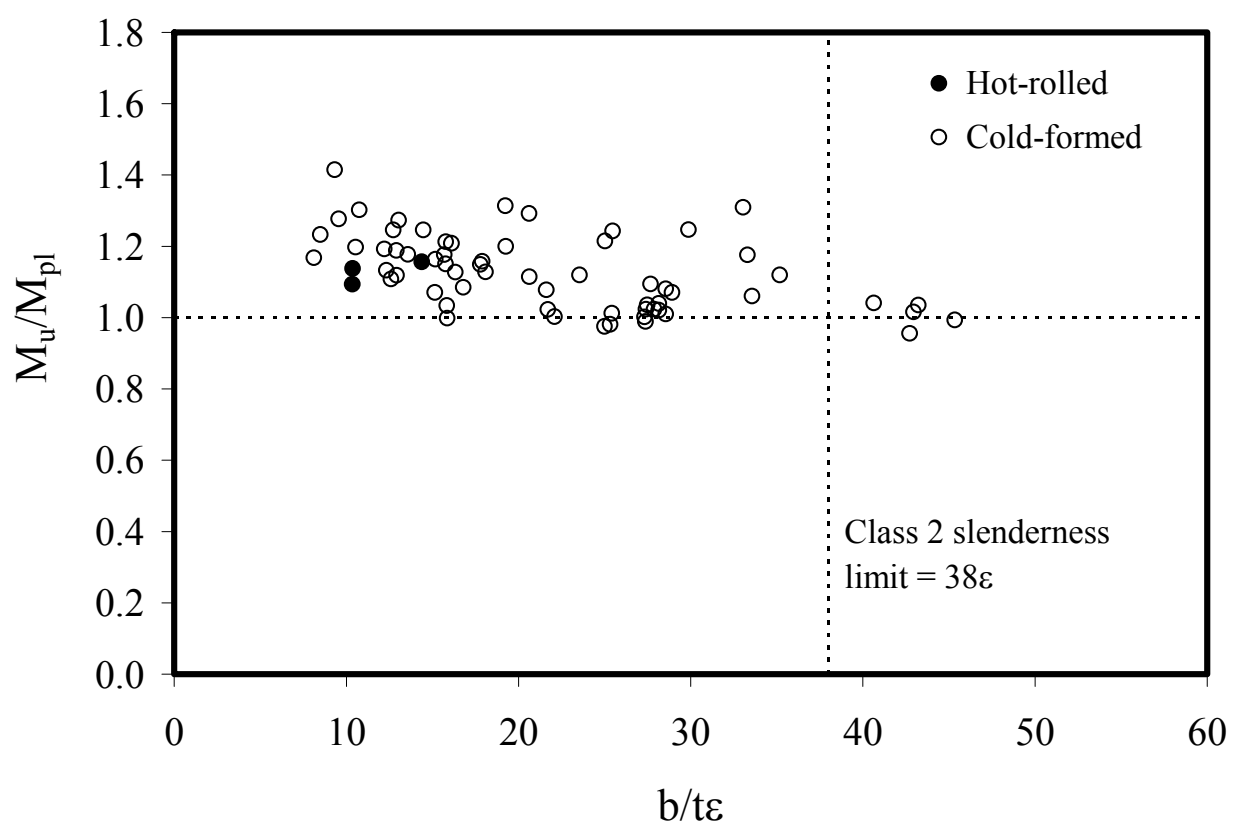

Fig. 25: $\mathrm{M}_{\mathrm{u}} / \mathrm{M}_{\mathrm{pl}}$ versus $\mathrm{b} / \mathrm{t} \varepsilon$ for assessment of Class 2 slenderness limit

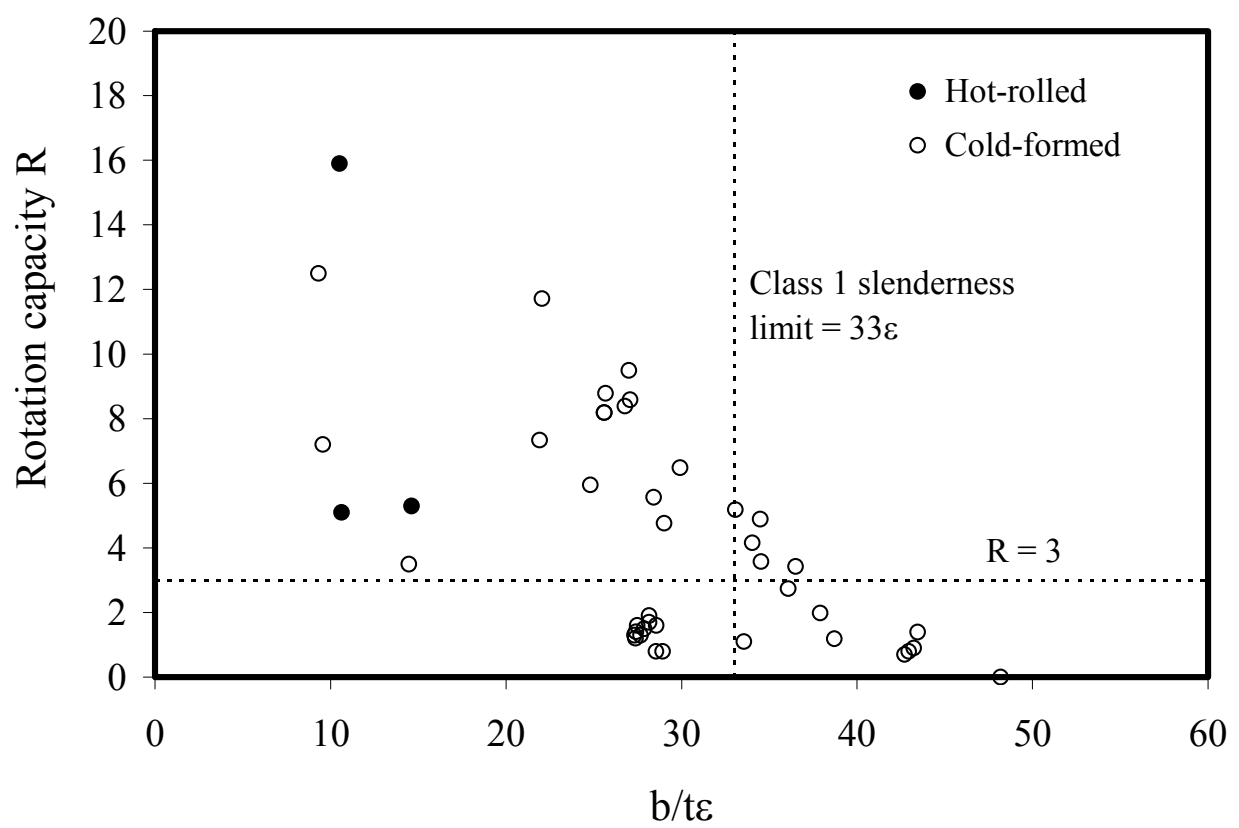

Fig. 26: Rotation capacity $\mathrm{R}$ versus $\mathrm{b} / \mathrm{t} \varepsilon$ for assessment of Class 1 slenderness limit 


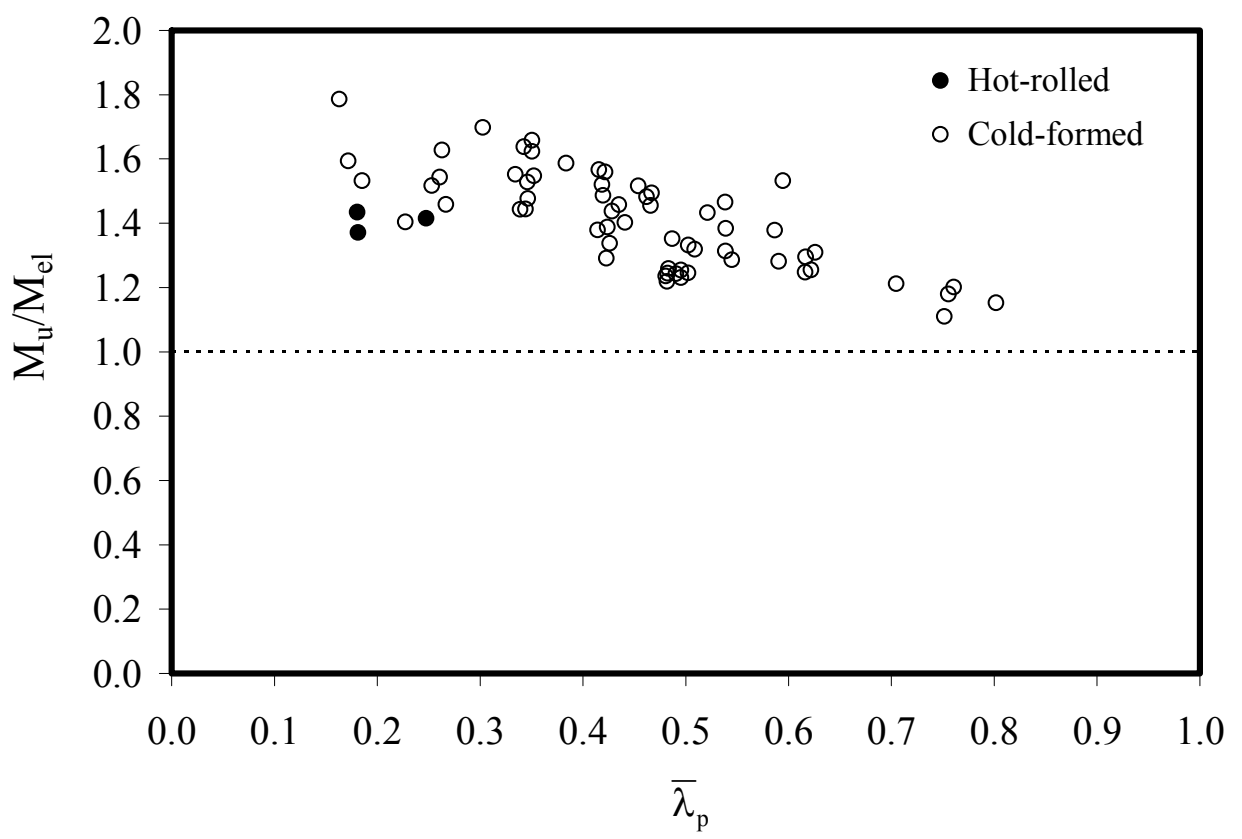

Fig. 27: $M_{u} / M_{e l}$ versus $\bar{\lambda}_{p}$ for available tests on SHS and RHS beams

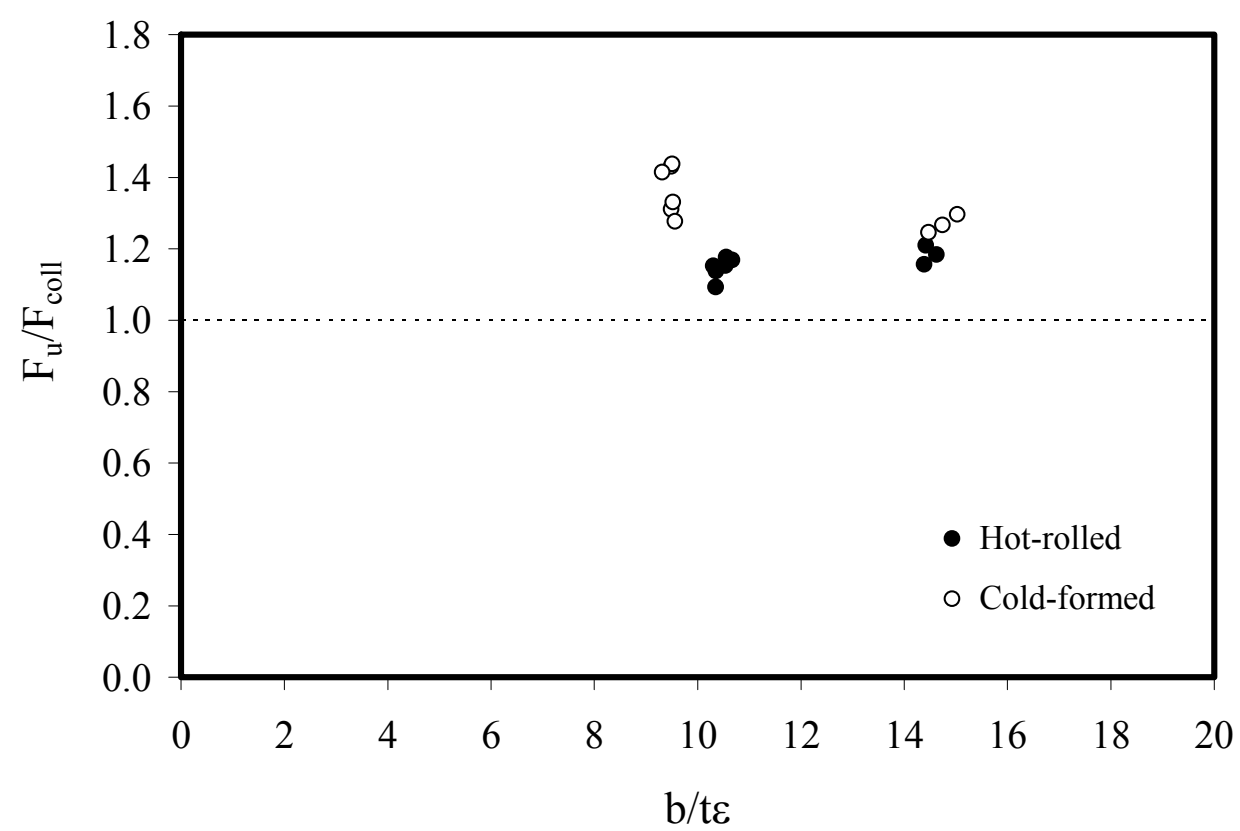

Fig. 28: $F_{u} / F_{\text {coll }}$ versus $b / t \varepsilon$ for continuous beam tests 
Table 1: Mill certificate (virgin) and measured tensile material properties of test specimens

\begin{tabular}{|c|c|c|c|c|c|c|}
\hline \multirow{2}{*}{ Tensile test specimen } & \multicolumn{2}{|c|}{$\begin{array}{c}\text { Mill certificate (virgin) } \\
\text { material properties }\end{array}$} & \multicolumn{4}{|c|}{ Measured tensile material properties } \\
\hline & $\begin{array}{c}\sigma_{\mathrm{y}, \mathrm{mill}} \\
\left(\mathrm{N} / \mathrm{mm}^{2}\right)\end{array}$ & $\begin{array}{c}\sigma_{\mathrm{u}, \mathrm{mill}} \\
\left(\mathrm{N} / \mathrm{mm}^{2}\right)\end{array}$ & $\begin{array}{c}\sigma_{\mathrm{y}, \exp } \\
\left(\mathrm{N} / \mathrm{mm}^{2}\right)\end{array}$ & $\begin{array}{c}\sigma_{\mathrm{u}, \exp } \\
\left(\mathrm{N} / \mathrm{mm}^{2}\right)\end{array}$ & $\begin{array}{c}E_{\exp } \\
\left(\mathrm{N} / \mathrm{mm}^{2}\right)\end{array}$ & $\begin{array}{c}\varepsilon f, \exp \\
(-)\end{array}$ \\
\hline SHS $100 \times 100 \times 4-H R$ & 491 & 569 & 488 & 570 & 212600 & 0.33 \\
\hline SHS $100 \times 100 \times 4-C F$ & 378 & 423 & 482 & 500 & 208300 & 0.29 \\
\hline SHS $100 \times 100 \times 4-C F-C$ & - & - & 522 & 567 & 199900 & 0.15 \\
\hline SHS $60 \times 60 \times 3-H R$ & 478 & 574 & 449 & 555 & 215200 & 0.31 \\
\hline SHS $60 \times 60 \times 3-\mathrm{CF}$ & 395 & 423 & 361 & 402 & 207400 & 0.49 \\
\hline SHS $60 \times 60 \times 3-C F-C$ & - & - & 442 & 471 & 208000 & 0.21 \\
\hline RHS $60 \times 40 \times 4-H R$ & 482 & 561 & 468 & 554 & 213800 & 0.37 \\
\hline RHS $60 \times 40 \times 4-C F$ & 445 & 471 & 400 & 452 & 212000 & 0.21 \\
\hline RHS $60 \times 40 \times 4-C F-C$ & - & - & 480 & 570 & 202400 & 0.15 \\
\hline SHS $40 \times 40 \times 4-H R$ & 523 & 576 & 496 & 572 & 212300 & 0.34 \\
\hline SHS $40 \times 40 \times 4-H R-C$ & 523 & 576 & 499 & 578 & 215500 & 0.37 \\
\hline SHS $40 \times 40 \times 4-C F$ & 383 & 413 & 410 & 430 & 201600 & 0.38 \\
\hline SHS $40 \times 40 \times 4-C F-C$ & - & - & 479 & 507 & 210900 & 0.17 \\
\hline SHS $40 \times 40 \times 3-H R$ & 520 & 565 & 504 & 581 & 219600 & 0.36 \\
\hline SHS $40 \times 40 \times 3-C F$ & 430 & 456 & 451 & 502 & 212900 & 0.24 \\
\hline SHS $40 \times 40 \times 3-C F-C$ & - & - & 534 & 589 & 196700 & 0.16 \\
\hline
\end{tabular}


Table 2: Geometric properties and ultimate capacities of the stub columns

\begin{tabular}{|c|c|c|c|c|c|c|c|}
\hline $\begin{array}{l}\text { Stub column } \\
\text { specimen }\end{array}$ & $\begin{array}{c}\mathrm{L} \\
(\mathrm{mm})\end{array}$ & $\begin{array}{c}\mathrm{D} \\
(\mathrm{mm})\end{array}$ & $\begin{array}{c}\mathrm{B} \\
(\mathrm{mm})\end{array}$ & $\begin{array}{c}\mathrm{t} \\
(\mathrm{mm})\end{array}$ & $\begin{array}{c}\mathrm{r}_{\mathrm{i}} \\
(\mathrm{mm})\end{array}$ & $\begin{array}{c}\mathrm{A} \\
\left(\mathrm{mm}^{2}\right)\end{array}$ & $\begin{array}{c}\mathrm{F}_{\mathrm{u}} \\
(\mathrm{kN})\end{array}$ \\
\hline SHS $100 \times 100 \times 4-H R 1$ & 405.18 & 100.01 & 100.89 & 4.09 & 2.75 & 1543 & 706 \\
\hline SHS $100 \times 100 \times 4-H R 2$ & 405.15 & 99.83 & 100.84 & 4.11 & 2.75 & 1548 & 707 \\
\hline SHS $100 \times 100 \times 4-C F 1$ & 404.99 & 100.55 & 100.56 & 3.59 & 6.38 & 1342 & 660 \\
\hline SHS $100 \times 100 \times 4-C F 2$ & 404.84 & 100.75 & 100.68 & 3.61 & 6.13 & 1353 & 663 \\
\hline SHS $60 \times 60 \times 3-H R 1$ & 244.98 & 60.21 & 60.18 & 3.35 & 2.38 & 739 & 353 \\
\hline SHS $60 \times 60 \times 3-H R 2$ & 245.05 & 60.22 & 60.23 & 3.38 & 2.44 & 745 & 363 \\
\hline SHS $60 \times 60 \times 3-C F 1$ & 245.10 & 60.30 & 60.14 & 2.78 & 3.75 & 614 & 249 \\
\hline SHS $60 \times 60 \times 3-C F 2$ & 245.05 & 60.17 & 60.17 & 2.79 & 3.88 & 615 & 250 \\
\hline RHS $60 \times 40 \times 4-H R 1$ & 245.03 & 59.84 & 40.09 & 3.83 & 1.88 & 682 & 344 \\
\hline RHS $60 \times 40 \times 4-H R 2$ & 244.86 & 59.72 & 40.17 & 3.83 & 1.94 & 681 & 346 \\
\hline RHS $60 \times 40 \times 4-C F 1$ & 244.93 & 60.09 & 40.07 & 3.95 & 2.19 & 701 & 370 \\
\hline RHS $60 \times 40 \times 4-C F 2$ & 244.90 & 60.06 & 40.00 & 3.97 & 1.94 & 705 & 370 \\
\hline SHS $40 \times 40 \times 4-H R 1$ & 165.18 & 40.00 & 39.94 & 3.91 & 2.06 & 537 & 333 \\
\hline SHS $40 \times 40 \times 4-H R 2$ & 165.08 & 40.05 & 39.94 & 3.91 & 2.25 & 536 & 335 \\
\hline SHS $40 \times 40 \times 4-C F 1$ & 165.05 & 40.36 & 40.32 & 3.76 & 3.13 & 518 & 256 \\
\hline SHS $40 \times 40 \times 4-C F 2$ & 165.23 & 40.32 & 40.31 & 3.79 & 3.06 & 522 & 256 \\
\hline SHS $40 \times 40 \times 3-H R 1$ & 165.00 & 40.25 & 40.23 & 3.05 & 2.13 & 435 & 263 \\
\hline SHS $40 \times 40 \times 3-H R 2$ & 165.18 & 40.16 & 40.10 & 3.05 & 2.00 & 434 & 257 \\
\hline SHS $40 \times 40 \times 3-C F 1$ & 165.23 & 40.12 & 40.13 & 2.76 & 2.56 & 394 & 224 \\
\hline SHS $40 \times 40 \times 3-C F 2$ & 165.06 & 40.04 & 40.07 & 2.75 & 2.69 & 391 & 230 \\
\hline
\end{tabular}

Table 3: Measured dimensions of simply supported beam specimens (three-point bending)

\begin{tabular}{|c|c|c|c|c|c|c|}
\hline $\begin{array}{l}\text { Simple beam } \\
\text { specimen }\end{array}$ & $\begin{array}{c}\mathrm{D} \\
(\mathrm{mm})\end{array}$ & $\begin{array}{c}\mathrm{B} \\
(\mathrm{mm})\end{array}$ & $\begin{array}{c}\mathrm{t} \\
(\mathrm{mm})\end{array}$ & $\begin{array}{c}\mathrm{r}_{\mathrm{i}} \\
(\mathrm{mm})\end{array}$ & $\begin{array}{c}\mathrm{W}_{\mathrm{el}} \\
\left(\mathrm{mm}^{3}\right)\end{array}$ & $\begin{array}{c}\mathrm{W}_{\mathrm{pl}} \\
\left(\mathrm{mm}^{3}\right)\end{array}$ \\
\hline RHS $60 \times 40 \times 4-H R$ & 60.09 & 40.24 & 3.90 & 1.91 & 10600 & 13400 \\
\hline RHS $60 \times 40 \times 4-C F$ & 60.04 & 40.09 & 3.93 & 2.07 & 10600 & 13400 \\
\hline SHS $40 \times 40 \times 4-H R$ & 39.75 & 40.00 & 3.91 & 2.16 & 5650 & 7080 \\
\hline SHS $40 \times 40 \times 4-C F$ & 40.31 & 40.42 & 3.70 & 3.10 & 5520 & 6900 \\
\hline SHS $40 \times 40 \times 3-H R$ & 39.87 & 40.20 & 3.05 & 2.07 & 4820 & 5900 \\
\hline SHS $40 \times 40 \times 3-C F$ & 40.16 & 40.11 & 2.80 & 2.63 & 4520 & 5500 \\
\hline
\end{tabular}


Table 4: Key results from simple beam tests (three-point bending)

\begin{tabular}{|c|c|c|c|c|c|c|c|c|c|}
\hline $\begin{array}{l}\text { Simple beam } \\
\text { specimen }\end{array}$ & $\begin{array}{c}\mathrm{M}_{\mathrm{u}} \\
(\mathrm{kNm})\end{array}$ & $\begin{array}{c}\mathrm{M}_{\mathrm{pl}} \\
(\mathrm{kNm})\end{array}$ & $\begin{array}{c}\mathrm{Mel}_{\mathrm{el}} \\
(\mathrm{kNm})\end{array}$ & $\mathrm{M}_{\mathrm{u}} / \mathrm{M}_{\mathrm{pl}}$ & $\mathrm{M}_{\mathrm{u}} / \mathrm{Mel}_{\mathrm{el}}$ & $\begin{array}{c}\theta_{\mathrm{pl}} \\
\text { (rad.) }\end{array}$ & $\begin{array}{c}\theta_{\mathrm{u}} \\
\text { (rad.) }\end{array}$ & $\begin{array}{l}\theta_{\text {rot }} \text { or } \theta_{\max } \\
\quad \text { (rad.) }\end{array}$ & $\mathrm{R}$ \\
\hline RHS $60 \times 40 \times 4-H R$ & 7.14 & 6.27 & 4.97 & 1.14 & 1.44 & 0.044 & 0.46 & 0.74 & $>15.9$ \\
\hline RHS $60 \times 40 \times 4-C F$ & 7.59 & 5.37 & 4.25 & 1.42 & 1.79 & 0.041 & 0.24 & 0.55 & $>12.5$ \\
\hline SHS $40 \times 40 \times 4-H R$ & 3.84 & 3.51 & 2.80 & 1.09 & 1.37 & 0.083 & 0.51 & 0.51 & $>5.1$ \\
\hline SHS $40 \times 40 \times 4-C F$ & 3.61 & 2.83 & 2.26 & 1.28 & 1.59 & 0.061 & 0.17 & 0.50 & $>7.2$ \\
\hline SHS $40 \times 40 \times 3-H R$ & 3.44 & 2.97 & 2.43 & 1.16 & 1.42 & 0.094 & 0.19 & 0.60 & $>5.3$ \\
\hline SHS $40 \times 40 \times 3-C F$ & 3.09 & 2.48 & 2.04 & 1.25 & 1.52 & 0.085 & 0.25 & $0.39^{\mathrm{a}}$ & 3.5 \\
\hline
\end{tabular}

Note: ${ }^{\text {a }} \theta_{\text {rot }}$ attained; $\theta_{\max }$ reported for remaining sections

Table 5: Measured dimensions of continuous beams (five-point bending)

\begin{tabular}{|c|c|c|c|c|c|c|c|}
\hline $\begin{array}{l}\text { Continuous beam } \\
\text { specimen }\end{array}$ & Configuration & $\mathrm{D}(\mathrm{mm})$ & $\mathrm{B}(\mathrm{mm})$ & $\mathrm{t}(\mathrm{mm})$ & $\mathrm{ri}_{\mathrm{i}}(\mathrm{mm})$ & $\begin{array}{c}\mathrm{W}_{\mathrm{el}} \\
\left(\mathrm{mm}^{3}\right)\end{array}$ & $\begin{array}{c}\mathrm{W}_{\mathrm{pl}} \\
\left(\mathrm{mm}^{3}\right)\end{array}$ \\
\hline RHS $60 \times 40 \times 4-H R 1$ & 1/2 Span & 60.09 & 40.27 & 3.85 & 1.91 & 10500 & 13300 \\
\hline RHS $60 \times 40 \times 4-C F 1$ & 1/2 Span & 60.14 & 40.20 & 3.89 & 2.07 & 10600 & 13400 \\
\hline RHS $60 \times 40 \times 4-C F 2$ & 1/2 Span & 60.15 & 40.08 & 3.87 & 2.07 & 10500 & 13300 \\
\hline SHS $40 \times 40 \times 4-H R 1$ & 1/2 Span & 39.79 & 39.98 & 3.85 & 2.16 & 5600 & 7010 \\
\hline SHS $40 \times 40 \times 4-C F 1$ & 1/2 Span & 40.37 & 40.36 & 3.72 & 3.10 & 5550 & 6930 \\
\hline SHS $40 \times 40 \times 3-H R 1$ & 1/2 Span & 39.90 & 40.22 & 3.01 & 2.07 & 4780 & 5850 \\
\hline SHS $40 \times 40 \times 3-C F 1$ & 1/2 Span & 40.08 & 40.20 & 2.72 & 2.63 & 4420 & 5370 \\
\hline RHS $60 \times 40 \times 4-H R 2$ & 1/3 Span & 60.06 & 40.33 & 3.82 & 1.91 & 10500 & 13200 \\
\hline SHS $40 \times 40 \times 4-H R 2$ & 1/3 Span & 39.93 & 39.78 & 3.90 & 2.16 & 5650 & 7090 \\
\hline SHS $40 \times 40 \times 4-C F 2$ & 1/3 Span & 40.43 & 40.36 & 3.71 & 3.10 & 5550 & 6930 \\
\hline SHS $40 \times 40 \times 3-H R 2$ & 1/3 Span & 40.21 & 39.91 & 3.02 & 2.07 & 4820 & 5890 \\
\hline SHS $40 \times 40 \times 3-\mathrm{CF} 2$ & 1/3 Span & 40.12 & 40.14 & 2.76 & 2.63 & 4470 & 5430 \\
\hline
\end{tabular}


Table 6: Summary of results from continuous beam tests

\begin{tabular}{|c|c|c|c|c|}
\hline $\begin{array}{l}\text { Continuous beam } \\
\text { specimen }\end{array}$ & $\begin{array}{l}\text { Ultimate test load } F_{u} \\
\qquad(\mathrm{kN})\end{array}$ & $\begin{array}{l}\text { Theoretical first } \\
\text { hinge load } \mathrm{F}_{\mathrm{h} 1}(\mathrm{kN})\end{array}$ & $\begin{array}{c}\text { Theoretical plastic } \\
\text { collapse load } \mathrm{F}_{\text {coll }}(\mathrm{kN})\end{array}$ & $\mathrm{F}_{\mathrm{u}} / \mathrm{F}_{\text {coll }}$ \\
\hline RHS $60 \times 40 \times 4-H R 1$ & 78.1 & 60.2 & 67.8 & 1.15 \\
\hline RHS $60 \times 40 \times 4-C F 1$ & 83.4 & 51.8 & 58.3 & 1.43 \\
\hline RHS $60 \times 40 \times 4-C F 2$ & 83.3 & 51.5 & 57.9 & 1.44 \\
\hline SHS $40 \times 40 \times 4-H R 1$ & 44.6 & 33.7 & 37.9 & 1.18 \\
\hline SHS $40 \times 40 \times 4-C F 1$ & 40.6 & 27.5 & 31.0 & 1.31 \\
\hline SHS $40 \times 40 \times 3-H R 1$ & 38.1 & 28.6 & 32.1 & 1.18 \\
\hline SHS $40 \times 40 \times 3-C F 1$ & 34.2 & 23.5 & 26.4 & 1.30 \\
\hline RHS $60 \times 40 \times 4-H R 2$ & 98.4 & 60.6 & 84.2 & 1.17 \\
\hline SHS $40 \times 40 \times 4-H R 2$ & 55.2 & 34.5 & 47.9 & 1.15 \\
\hline SHS $40 \times 40 \times 4-C F 2$ & 51.5 & 27.9 & 38.7 & 1.33 \\
\hline SHS $40 \times 40 \times 3-H R 2$ & 49.0 & 29.1 & 40.5 & 1.21 \\
\hline SHS $40 \times 40 \times 3-C F 2$ & 42.3 & 24.0 & 33.4 & 1.27 \\
\hline
\end{tabular}

Table 7: Bending residual stress values for cold-formed sections

\begin{tabular}{l|cccc|cccc}
\hline \multirow{2}{*}{ Specimen } & \multicolumn{4}{|c|}{ Flat faces } & \multicolumn{4}{c}{ Corner regions } \\
\cline { 2 - 9 } & $\begin{array}{c}\sigma_{\mathrm{bl}} \\
\left(\mathrm{N} / \mathrm{mm}^{2}\right)\end{array}$ & $\begin{array}{c}\sigma_{\mathrm{br}} \\
\left(\mathrm{N} / \mathrm{mm}^{2}\right)\end{array}$ & $\sigma_{\mathrm{bl}} / \sigma_{0.2}$ & $\sigma_{\mathrm{br}} / \sigma_{0.2}$ & $\begin{array}{c}\sigma_{\mathrm{bl}} \\
\left(\mathrm{N} / \mathrm{mm}^{2}\right)\end{array}$ & $\begin{array}{c}\sigma_{\mathrm{br}} \\
\left(\mathrm{N} / \mathrm{mm}^{2}\right)\end{array}$ & $\sigma_{\mathrm{bl}} / \sigma_{0.2}$ & $\sigma_{\mathrm{br}} / \sigma_{0.2}$ \\
\hline $100 \times 100 \times 4-\mathrm{CF}$ & 287 & 191 & 0.60 & 0.40 & 253 & 121 & 0.49 & 0.23 \\
$60 \times 60 \times 3-\mathrm{CF}$ & 262 & 175 & 0.73 & 0.48 & 267 & 130 & 0.60 & 0.29 \\
$60 \times 40 \times 4-\mathrm{CF}$ & 356 & 237 & 0.89 & 0.59 & 501 & 389 & 1.04 & 0.81 \\
$40 \times 40 \times 4-\mathrm{CF}$ & 379 & 253 & 0.92 & 0.62 & 370 & 211 & 0.77 & 0.44 \\
$40 \times 40 \times 3-\mathrm{CF}$ & 362 & 241 & 0.80 & 0.53 & 338 & 171 & 0.64 & 0.32 \\
\hline Mean & \multicolumn{1}{c}{} & & 0.79 & 0.52 & & & 0.71 & 0.42 \\
\hline
\end{tabular}

